\title{
Chronic AdipoRon Treatment Mimics the Effects of Physical Exercise on Restoring Hippocampal Neuroplasticity in Diabetic Mice
}

\author{
Thomas H Lee ${ }^{1}$ - Ahadullah ${ }^{1}$ • Brian R Christie ${ }^{2} \cdot$ Kangguang Lin $^{3} \cdot$ Parco Ming-fai Siu $^{4} \cdot$ Li Zhang $^{5} \cdot$ Ti-fei Yuan $^{6}$. \\ Pragya Komal ${ }^{7} \cdot$ Aimin $\mathrm{Xu}^{8,9} \cdot$ Kwok-fai So ${ }^{5,10} \cdot$ Suk-yu Yau ${ }^{1,11}$
}

Received: 24 March 2021 / Accepted: 25 May 2021 / Published online: 23 June 2021

(C) The Author(s) 2021

\begin{abstract}
Administration of exercise mimetic drugs could be a novel therapeutic approach to combat comorbid neurodegeneration and metabolic syndromes. Adiponectin is an adipocyte-secreted hormone. In addition to its antidiabetic effect, adiponectin mediates the antidepressant effect of physical exercise associated with adult hippocampal neurogenesis. The antidiabetic effect of the adiponectin receptor agonist AdipoRon has been demonstrated, but its potential pro-cognitive and neurotrophic effects in the hippocampus under diabetic condition are still unclear. This study reported that chronic AdipoRon treatment for 2 weeks improved hippocampal-dependent spatial recognition memory in streptozotocin-induced diabetic mice. Besides, AdipoRon treatment increased progenitor cell proliferation and neuronal differentiation in the hippocampal dentate gyrus (DG) of diabetic mice. Furthermore, AdipoRon treatment significantly increased dendritic complexity, spine density, and $N$-methyl-D-aspartate receptor-dependent long-term potentiation (LTP) in the dentate region, and increased BDNF levels in the DG of diabetic mice. AdipoRon treatment activated AMPK/PGC-1 $\alpha$ signalling in the DG, whereas increases in cell proliferation and LTP were not observed when PGC- $1 \alpha$ signalling was pharmacologically inhibited. In sum, chronic AdipoRon treatment partially mimics the benefits of physical exercise for learning and memory and hippocampal neuroplasticity in the diabetic brain. The results suggested that AdipoRon could be a potential physical exercise mimetic to improve hippocampal plasticity and hence rescue learning and memory impairment typically associated with diabetes.
\end{abstract}

Keywords AdipoRon $\cdot$ Adiponectin $\cdot$ Diabetes $\cdot$ Adult neurogenesis $\cdot$ Hippocampal plasticity $\cdot$ Cognitive impairment $\cdot$ Physical exercise

Suk-yu Yau

sonata.yau@polyu.edu.hk

1 Department of Rehabilitation Sciences, Faculty of Health and Social Sciences, The Hong Kong Polytechnic University, 11 Yuk Choi Road, Hung Hom, Hong Kong SAR

2 Division of Medical Sciences, University of Victoria, Victoria, British Columbia, Canada

3 Department of Affective Disorder, Guangzhou Brain Hospital, The Affiliated Brain Hospital of Guangzhou Medical University, Guangzhou, China

4 School of Public Health, LKS Faculty of Medicine, The University of Hong Kong, Pokfulam, Hong Kong SAR

5 Key Laboratory of CNS Regeneration (Ministry of Education), Guangdong-Hong Kong-Macau Institute of CNS Regeneration, Jinan University, Guangzhou, China
6 Shanghai Mental Health Center, School of Medicine, Shanghai Jiao Tong University, Shanghai, China

7 Department of Biological Sciences, Birla Institute of Technology and Sciences (BITS-Pilani Hyderabad), Hyderabad, India

8 Department of Pharmacology and Pharmacy, LKS Faculty of Medicine, The University of Hong Kong, Pokfulam, Hong Kong SAR

9 State Key Laboratory of Pharmaceutical Biotechnology, The University of Hong Kong, Pokfulam, Hong Kong SAR

10 State Key Laboratory of Brain and Cognitive Science, The University of Hong Kong, Pokfulam, Hong Kong SAR

11 University Research Facility in Behavioral and Systems Neuroscience, The Hong Kong Polytechnic University, Hung Hom, Hong Kong SAR 


\section{Introduction}

Epidemiological studies have reported that diabetes is a risk factor for developing dementia $(1,2)$. Rodent models of diabetes also display cognitive decline (3-6) associated with impaired adult neurogenesis in the dentate gyrus ( 7 , $8)$, synaptic deficits $(9,10)$, and neuroinflammation (11, 12). The term type 3 diabetes signifies Alzheimer's disease (AD) as a metabolic-cognitive syndrome, reflecting the concurrence of insulin resistance and neurodegeneration in AD brains (13). Physical exercise is an effective nonpharmacological intervention for cognitive decline in neurodegeneration and diabetes (14-16) by promoting synaptic plasticity (17) and adult hippocampal neurogenesis (18). However, chronic inactivity (19-21), mood disorder (22-24), and physical disability $(25,26)$ may undermine the beneficial effects of physical exercise on metabolic and brain health in the elderly under severe obese and diabetic conditions.

Activating a common molecular target that mediates the eumetabolic and pro-cognitive effects of physical exercise can be a novel therapeutic approach to combat diabetes and its associated neurodegeneration. The adipocyte-secreted hormone adiponectin is deemed to be a worthy candidate since it possesses antidiabetic property by promoting insulin sensitivity (27). Hypoadiponectinemia is restored in obese and diabetic individuals undergoing physical exercise interventions $(28,29)$. The central adiponectin level could be linked to neurodegeneration and cognitive decline as suggested by reduced adiponectin levels in the hippocampus of diabetic mice (30) and cerebrospinal fluid of AD patients (31). Importantly, further studies have unravelled the pivotal role of adiponectin in cognitive function and hippocampal plasticity. Learning and memory deficits are presented in adiponectin-deficient mice (32). Also, adiponectin regulates dendritic and spine formation (33) as well as synaptic plasticity (32) in the hippocampus, where adiponectin receptors 1 and 2 (AdipoR1 and AdipoR2) are expressed in the hippocampal neural progenitor cells (34), neurons (35), and synapses (32). Our team has previously shown that adiponectin mediates exercise-induced adult neurogenesis, dendritic arborisation, and AMP-activated protein kinase (AMPK) activation in the hippocampus $(30,34,36)$. BDNF is a crucial downstream effector to regulate adult neurogenesis, synaptic plasticity, and cognitive function (37). The concomitant increases in brain-derived neurotrophic factor (BDNF) and adult hippocampus neurogenesis mimic the beneficial effects of voluntary running on cognitive enhancement in mice (38). Notably, activating PGC- $1 \alpha$ signalling is required for physical exercise to increase BDNF levels (39) and dendritic spine formation (40) in the hippocampus. In addition, an early study has demonstrated that adiponectin promotes PGC- $1 \alpha$ activity through AdipoR1/AMPK signalling (41). These studies collectively suggest that activating adiponectin signalling cascade may contribute to raising BDNF level.

Administration of AdipoRon, an agonist of AdipoR1 and AdipoR2, resembles the effects of adiponectin administration and physical exercise on improving insulin sensitivity and oxidative metabolism in diabetic mice (42). Since AdipoRon can cross the blood-brain barrier $(31,43)$, this study aimed to investigate whether chronic treatment with AdipoRon could act as a pro-cognitive exercise mimetic to restore hippocampal neuroplasticity in animals experiencing diabetes-associated hippocampal dysfunction.

\section{Materials and Methods}

\section{Animals and Experimental Design}

All experimental procedures were approved and followed the Animal Subjects Ethics Sub-Committee's guidelines at The Hong Kong Polytechnic University. Five-week-old C57BL/ $6 \mathrm{~J}$ male mice were fed with standard chow and water ad libitum and kept under a 12-h light-dark cycle. A singledose streptozotocin (STZ; $195 \mathrm{mg} / \mathrm{kg}$ i.p.) (Santa Cruz Biotechnology Ltd., USA) was delivered intraperitoneally to induce diabetes-associated hippocampal impairment as previously described (30). Tail blood samples were measured by glucometer (Accu-Chek ${ }^{\circledR}$ Performa, Australia) 7 days after STZ administration, and only animals that exhibited hyperglycaemia ( $\geq 20 \mathrm{mmol} / \mathrm{L}$ ) were included in the experiments (Fig. S1).

AdipoRon $(20 \mathrm{mg} / \mathrm{kg}$ in $0.5 \%$ carboxymethylcellulose salt solution, i.p. injection) (Sigma-Aldrich, MO, USA) or vehicle was delivered continuously for 14 days (44). In the voluntary exercise regime, mice were group housed in the holding cage, with shared running wheels as previously described $(30,34)$. Mice were injected with bromodeoxyuridine i.p. $(50 \mathrm{mg} / \mathrm{kg}$ in $0.9 \%$ saline) before AdipoRon treatment to label surviving new-born cell in the DG. The day after the last treatment, mice were subjected to the open field test and Y-maze task (Fig. 1A).

\section{Behavioural Tests}

\section{Open Field Test}

Mice were brought to the testing room $2 \mathrm{~h}$ prior to the test for adaptation (44). Each mouse was allowed to explore the open field $(\mathrm{L} \times \mathrm{W} \times \mathrm{H}: 40 \times 40 \times 30 \mathrm{~cm}$ ) for $10 \mathrm{~min}$ in dim light. Anxiety-like behaviour and locomotor activity were analysed by ANYMAZE software (Stoelting Co., IL, USA). Locomotor activity was presented as the total distance travelled over $10 \mathrm{~min}$. 

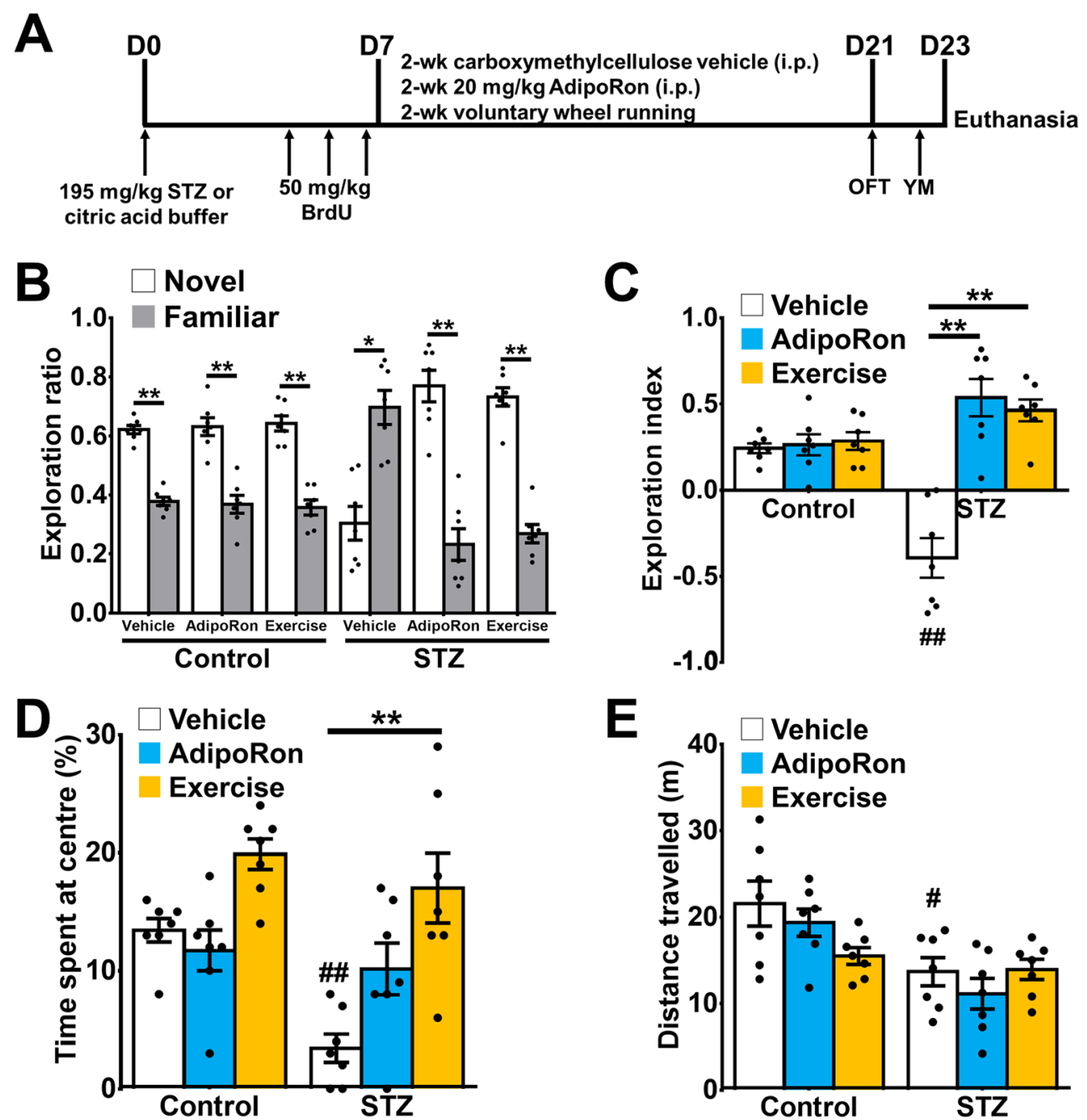

Fig. 1 AdipoRon treatment ameliorated diabetes-associated spatial recognition memory. A Animal treatment timeline ( $n=7$ animals per group). Previously reported Control-Vehicle and Control-AdipoRon data were used to support this study and are available at doi: 10.3390/ijms22042068 (44). B Exploration ratios in Y-maze. Neither AdipoRon treatment nor exercise altered novelty preference in the Y-maze in healthy control mice. Diabetic mice showed impairment in Y-maze as shown with a greater preference towards the familiar arm (paired $t$-test: $* P<0.005$ vs. Novel arm), while both AdipoRon treatment and exercise restored the memory deficit in diabetic mice $(* * P<0.005$ vs. Novel arm). C Exploration indices in Y-maze. Diabetic mice presented spatial memory

\section{Y-Maze Task}

Three identical arms $(\mathrm{L} \times \mathrm{W} \times \mathrm{H}: 10 \times 6 \times 8 \mathrm{~cm})$ in $\mathrm{Y}$-maze were pre-designated as the starting arm, the familiar arm, and the novel arm, respectively (44). Three arms were counterbalanced to avoid recognition bias. Tests were carried out in the dim light setting. In the 10-min habituation session, a mouse was released in the designated starting arm and was allowed to explore the maze with a blocked novel arm. After a 4-h intermission, the mouse was allowed to explore the maze with the unblocked novel arm for $5 \mathrm{~min}$. Time spent in each arm was hand-scored by the trained researcher in a sample-

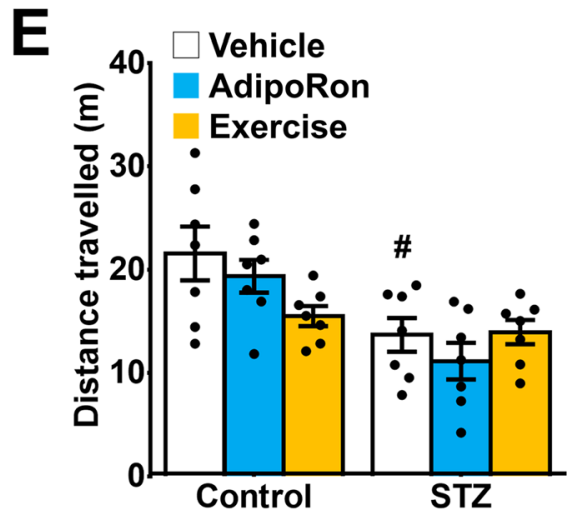

deficit (Tukey's post hoc test: ${ }^{\# \#} P<0.005$ vs. Control-Vehicle), whereas AdipoRon treatment (Tukey's post hoc test: $* * P<0.005$ vs. STZVehicle) and exercise (Tukey's post hoc test: $* * P<0.005$ vs. STZVehicle) ameliorated memory deficit. D Diabetic mice showed anxietylike behaviour (Tukey's post hoc test: ${ }^{\# \#} P<0.005$ vs. Control-Vehicle), which could be restored by exercise (Tukey's post hoc test: $* * P<0.005$ vs. STZ-Vehicle). E Diabetic mice had reduced locomotor activity (Tukey's post hoc test: ${ }^{\#} P<0.05$ vs. Control-Vehicle). AdipoRon treatment and exercise (Tukey's post hoc test: $P>0.05$ vs. STZ-Vehicle) did not improve locomotor activity in diabetic mice

blinded manner. Exploration ratios were calculated as (time spent in the novel arm $(\mathrm{N}) /($ time spent in novel + familiar arms) and (time spent in the familiar arm (F))/(time spent in novel + familiar arms), and an exploration index (in a -1 to 1 scale) was calculated as $(\mathrm{N}-\mathrm{F}) /(\mathrm{N}+\mathrm{F})$.

\section{Tissue Preparation for Immunostaining}

Mice were deeply anaesthetised with isoflurane (Zoetis, UK). Blood samples were collected transcardially by using a $1-\mathrm{mL}$ syringe with a $25-\mathrm{G}$ needle. Blood samples were clotted for $30 \mathrm{~min}$ at room temperature, and blood serum samples were 
collected by centrifugation at $1,000 \mathrm{~g}$ for $20 \mathrm{~min}$ at $4{ }^{\circ} \mathrm{C}$, and then stored at $-80{ }^{\circ} \mathrm{C}$ until measurements using enzymelinked immunosorbent assay (ELISA). Animals were then perfused with $0.9 \%$ saline, followed by $4 \%$ paraformaldehyde (PFA) in $0.01 \mathrm{M}$ phosphate-buffered saline (PBS). The isolated brains were post-fixed with $4 \%$ PFA at $4{ }^{\circ} \mathrm{C}$ overnight. The brains were then stored in $30 \%$ sucrose until they sank. Coronal sections (1-in-6 series, 30- $\mu$ m thickness) were prepared using a vibratome (Leica Biosystems, Germany). The brain slices were stored in cryoprotectant (30\% glycerol and $30 \%$ ethylene glycol) at $4{ }^{\circ} \mathrm{C}$ until immunostaining.

\section{Immunohistochemistry}

Immunostaining was performed by the free-floating method as previously performed (44). For BrdU staining, the antigens were retrieved in the citric acid buffer $(\mathrm{pH} 6.0)$ at $95^{\circ} \mathrm{C}$ for 15 min, then denatured in $2 \mathrm{~N} \mathrm{HCl}$ for $30 \mathrm{~min}$ and neutralised by $0.1 \mathrm{M}$ borate buffer $(\mathrm{pH} 8.5$ ) for $15 \mathrm{~min}$ at room temperature. The sections were incubated overnight with mouse anti-BrdU antibody (1:1,000; Roche Life Science, Germany) and then incubated with the biotinylated goat anti-mouse $\operatorname{IgG}(1: 200$; Vector Laboratories, CA, USA) for $2 \mathrm{~h}$ at room temperature. For doublecortin (DCX) and Ki-67 staining, sections were incubated with mouse anti-DCX $(1: 200$; Santa Cruz Biotechnology, TX, USA) or rabbit anti-Ki67 (1:1,000; Abcam, UK) antibodies, then secondary antibodies: biotinylated goat anti-mouse or goat anti-rabbit $\operatorname{IgG}$ (1:200; Vector Laboratories, CA, USA). Positive staining was visualised with the peroxidase method using the VECTASTAIN® ABC kit (HRP) (Vector Laboratories, CA, USA) and the DAB peroxidase substrate kit (Vector Laboratories, CA, USA).

\section{Immunofluorescent Co-labelling}

Immunofluorescent co-labelling of BrdU and DCX was performed as previously described $(34,44)$. After antigen retrieval, sections were incubated with primary antibodies overnight and secondary antibodies: goat anti-rabbit IgG Alexa Fluor488 and goat anti-mouse IgG Alexa Fluor-568 for $2 \mathrm{~h}$ at room temperature. After washes with PBS, the sections were counterstained by DAPI and coverslipped with the fluorescent mounting medium (Dako, CA, USA).

\section{Quantifications of BrdU+, Ki67+, and DCX+ cells}

Cells were counted in the 1-in-6 series of nine sections (from bregma -1.34 to $-3.80 \mathrm{~mm}$ ), using optical fractionators system (grid size: $55 \mu \mathrm{m} \times 55 \mu \mathrm{m}$; counting frame: $35 \mu \mathrm{m} \times 35$ $\mu \mathrm{m})$ of Stereo Investigator (MicroBrightField Inc., VT, USA) as previously described (44). Cells located in the dentate subgranular zone and granular cell layer were counted, whereas those located in the uppermost focal plane were excluded. Quantification was performed in a sample-blinded manner.

\section{Quantifications of DCX+/BrdU+ co-labelled cells}

Images of six sections from each animal were captured using LSM 800 confocal laser scanning microscope (Carl Zeiss Microscopy, NY, USA). Fifty BrdU positive cells were randomly selected, followed by confirming the DCX co-labelled ratio to indicate neuronal differentiation $(34,45)$. Quantification of the co-labelling was performed in a sample-blinded manner $(30,44)$.

\section{Golgi Staining}

Golgi staining was performed using the commercially available FD Rapid GolgiStain ${ }^{\mathrm{TM}}$ Kit (FD Neurotechnologies, Inc., MD, USA). Solutions A and B in FD Rapid GolgiStain ${ }^{\text {TM Kit }}$ were pre-mixed in a 1:1 ratio for a week. Mice were deeply anaesthetised by isoflurane (Zoetis, UK) and rapidly decapitated to obtain the whole brain. The hemispheres were halved and kept in solution A-B mixture in the dark at room temperature for 6 days. Then, the halved brains were immersed in cryoprotectant at $4{ }^{\circ} \mathrm{C}$ in the dark until they sank. Cryoprotectant was replaced after the first $24 \mathrm{~h}$. Coronal brain slices with $200-\mu \mathrm{m}$ thickness were obtained from rostral to caudal (from bregma -1.34 to $-3.80 \mathrm{~mm}$ ) using a vibratome (Leica Biosystems, Germany) filled with ice-cold, $6 \%$ sucrose solution. Sections were immediately mounted onto a chrome alum-coated slide with solution $\mathrm{C}$ and dried in a dark chamber overnight at room temperature. The staining solution was freshly prepared by mixing solution $\mathrm{D}$, solution $\mathrm{E}$, and Milli-Q water in 1:1:2 ratio. Samples were stained for $10 \mathrm{~min}$ and were briefly rinsed by Milli-Q water. At last, dried samples were dehydrated through $70 \%, 90 \%$, and $100 \%$ ethanol (5 min each, $10 \mathrm{~min}$ for absolute ethanol) and xylene for $15 \mathrm{~min}$. Samples were then coverslipped.

\section{Dendritic Branch Analyses}

Granule cells were selected based on the following criteria (45-48): (1) Neuronal cell bodies located in the middle part of the section thickness to minimise the truncated branch segments; (2) consistent impregnation along with the entire extent of all dendrites; (3) located in the appropriate subregion of the dorsal hippocampi. Specifically, granule cells in the hippocampal DG were selected based on their soma position because granule cells with different soma position in the dentate gyrus could have different morphologies. Granule cells located closer to the subgranular zone show a simpler dendritic architecture with typically one primary dendrite extension. The granule cells located in the outer granule cell layer display 
multiple primary dendritic extensions and have more complex dendritic branching. Single-branched granule cells were selected from the inner cell layer, and multiple-branched granule cells were selected from the outer cell layer as previously performed (45-48). Five single-branched and five multiplebranched granule cells were selected from each sample to measure the total dendritic length, and Sholl analysis was performed using Neurolucida (MicroBrightField Bioscience, VT, USA).

\section{Dendritic Spine Analyses}

Five single-branched and five multiple-branched granule cells were selected from each sample. Five segments of tertiary or quaternary dendritic branches (longer than $15 \mu \mathrm{m}$ ) were selected from a granule cell using $\times 400$ magnification under a light microscope (Axioplan, Zeiss, Oberkochen, Germany) $(45,47)$. Quantification of dendritic spines was performed using $\times 630$ magnification.

\section{Protein Extraction}

Mice were rapidly decapacitated. The hippocampal DG was isolated from the Ammon's horn as previously described (49). The dentate gyrus samples were homogenised from a pool of seven mice from the same treatment group in ice-cold radioimmunoprecipitation assay buffer (Abcam, Cambridge, UK) containing Halt $\odot$ phosphatase/protease cocktail (Thermo Fisher Scientific, Waltham, MA, USA) and phenylmethanesulfonyl fluoride (Thermo Fisher Scientific, Waltham, MA, USA). Samples were then sonicated for $20 \mathrm{~s}$ with a $50 \%$ pulse. Supernatants were collected by centrifugation $(14,000 \mathrm{~g})$ at $4{ }^{\circ} \mathrm{C}$ for $30 \mathrm{~min}$. Protein concentrations of supernatant were quantified by Bradford assay (Bio-Rad Laboratories, Hercules, CA, USA) and stored at $-80^{\circ} \mathrm{C}$.

\section{Western Blotting}

Homogenates were heat linearised in $1 \times$ laemmli buffer (BioRad Laboratories, Hercules, CA, USA) with $5 \% \beta-$ mercaptoethanol (Abcam, Cambridge, UK) for $10 \mathrm{~min}$. Homogenate containing $50 \mu \mathrm{g}$ protein was loaded in a lane. Proteins were separated by $10 \%$ TGX stain-free FastCast $\odot$ SDS gel (Bio-Rad Laboratories, Hercules, CA, USA) and transferred to polyvinylidene fluoride (PVDF) membranes (Bio-Rad Laboratories, Hercules, CA, USA). Blocking solution contains $5 \%$ non-fat dry milk powder (Bio-Rad Laboratories, Hercules, CA, USA) for non-phosphorylated protein targets or $5 \%$ bovine serum albumin (Sigma, MO, USA) for phosphor-protein targets in the Tris- $\mathrm{HCl}$ buffer ( $\mathrm{pH}$ 8.0). After 1-h blocking, membranes were incubated overnight with primary antibodies in blocking solution with $0.05 \%$ Tween 20 . Primary antibodies from the rabbit are used:
pAMPK $\alpha^{\text {Thr172 }}$ (1:1,000, Cell Signaling), AMPK $\alpha$ (1:1,000, Cell Signaling), pPGC1 $\alpha^{\text {Ser571 }}(1: 1,000$, R\&D systems), PGC1- $\alpha$ (1:1000, Millipore), $\beta$-actin $(1: 5,000$, Cell Signaling). After three washes, membranes were probed for $1 \mathrm{~h}$ with the horseradish peroxidase-conjugated secondary antibodies. After the final three washes, bands were developed by enhanced chemiluminescent (ECL) detection kit (Santa Cruz Biotechnology, Inc., Dalla, TX, USA) and documented by a transilluminator (Bio-Rad Laboratories, Hercules, CA, USA). Band intensities were subjected to densitometric analysis in the Image Lab software (Bio-Rad Laboratories, Hercules, CA, USA).

\section{Tissue Preparation for Electrophysiology}

Brain slices were prepared as previously described (50). Adult male animals (8-9 weeks old) were deeply anaesthetised with isoflurane and rapidly decapitated. The brains were isolated and immersed in a chilled artificial cerebrospinal fluid (ACSF) containing (in mM) $125 \mathrm{NaCl}, 25 \mathrm{NaHCO}_{3}, 3 \mathrm{KCl}, 1.25$ $\mathrm{NaH}_{2} \mathrm{PO}_{4}, 10 \mathrm{D}$-glucose, $1 \mathrm{CaCl}_{2}$, and $6 \mathrm{MgCl}_{2}$, and saturated with $95 \% \mathrm{O}_{2} / 5 \% \mathrm{CO}_{2}$. Transverse brain slices (thickness: 350 $\mu \mathrm{m})$ were obtained using a semi-automatic vibratome (VT1000S, Leica Biosystems Inc., IL, USA). Slices were gently transferred to an incubation chamber filled with ACSF containing (in mM) $125 \mathrm{NaCl}, 25 \mathrm{NaHCO}_{3}, 3 \mathrm{KCl}$, $1.25 \mathrm{NaH}_{2} \mathrm{PO}_{4}, 10 \mathrm{D}$-glucose, $2 \mathrm{CaCl}_{2}$, and $1 \mathrm{MgCl}_{2}$, and saturated with $95 \% \quad \mathrm{O}_{2} / 5 \% \mathrm{CO}_{2}$. Slices were allowed to recover at $35{ }^{\circ} \mathrm{C}$ for a minimum of $1 \mathrm{~h}$ before recording.

\section{Long-term Potentiation Field Recording}

Hippocampal DG was positioned on the 64 extracellular electrodes in a recording probe (P515A, Alpha MED Scientific Inc., Osaka, Japan) to stimulate granule neurons in the middle molecular layer (medial perforant pathway) of the suprapyramidal blade. Recordings of field excitatory postsynaptic potentials (fEPSPs) were made on adjacent channels located midway between the crest and the distal end of the limb. Slices were perfused at a rate of approximately $2 \mathrm{~mL} /$ min. fEPSPs were acquired using the recording amplifiers (MED-A64MD1 and MED-A64HE1S, Alpha MED Scientific Inc., Osaka, Japan) connected to a Windows computer running Mobius software. For each slice, stimulus intensity $(20-35 \mu \mathrm{A})$ was adjusted to yield $40-50 \%$ of the maximal response slope without population spikes. Baselines fEPSP measurements were obtained by delivering single-pulse stimulation at 15-s interstimulus intervals. After a steady baseline of at least $20 \mathrm{~min}$, a conditioning protocol was used to induce synaptic plasticity, followed by baseline measurement for $1 \mathrm{~h}$ as previously performed (50). High-frequency stimulation (HFS) protocol (4 trains of 50 pulses, delivered at $100 \mathrm{~Hz}$ with 30 -s intertrain interval) was applied in the presence of 
bicuculline methiodide $(5 \mu \mathrm{M})$ to inhibit the $\gamma$-aminobutyric acid-A $\left(\mathrm{GABA}_{\mathrm{A}}\right)$ receptors and facilitate LTP induction in the DG. In pharmacological intervention, brain slices were acutely perfused in PEAQX tetrasodium hydrate $(0.1 \mu \mathrm{M}$; NVPAAM077) (Sigma-Aldrich, MO, USA) to inhibit GluN2A subunit (51) or in Ro 25-6981 maleate $(0.5 \mu \mathrm{M})$ (Alomone Labs, Israel) to inhibit GluN2B subunit (52) for $30 \mathrm{~min}$ before HFS. Similarly, SR-18292 maleate (1 nM; Sigma-Aldrich, MO, USA), a PGC- $1 \alpha$ blocker, was perfused 20 min before HFS. AdipoRon ( $500 \mathrm{nM}$ dissolved in aACSF) was bath perfused in the last $10 \mathrm{~min}$ in the presence of inhibitors.

\section{Immunoassays for Adiponectin and BDNF Levels}

Levels of adiponectin and BDNF in the collected sera and dentate gyri were determined by using the commercial ELISA kits, including mouse adiponectin ELISA kit for measuring serum adiponectin levels (Immunodiagnostics, University of Hong Kong, Hong Kong), mouse adiponectin ELISA kit for measuring adiponectin levels in the hippocampal DG (AdipoGen Life Sciences, Switzerland), and the total BDNF Quantikine ELISA kit (R\&D system, MN, USA) according to the manufacturer's instructions.

\section{N2a Mouse Neuroblastoma Cell Line Maintenance}

Murine neuroblastoma cell line N2a (ATCC, VA, USA) was maintained in the Gibco ${ }^{\circledR}$ Dulbecco's modified Eagle's medium (DMEM, Thermo Fisher Scientific, MA, USA) containing $10 \%$ foetal bovine serum (FBS), $2 \mathrm{mM} \mathrm{L}$-glutamine, and $50 \mu \mathrm{g} / \mathrm{mL}$ penicillin-streptomycin. After reaching $90 \%$ confluence, cell cultures were washed with Gibco ${ }^{\circledR}$ Dulbecco's PBS (DPBS, Thermo Fisher Scientific, MA, USA) and incubated with the mixture of $0.25 \%$ trypsin $/ 0.02 \%$ EDTA at 37 ${ }^{\circ} \mathrm{C}$ for $10 \mathrm{~min}$. Trypsinization was halted by FBS-containing DMEM. The cell suspension was pelleted at $300 \mathrm{~g}$ for $7 \mathrm{~min}$ and split in four. Passages 3-7 (the initial cell stock as passage 0 ) were used for the following assays.

\section{Cell Proliferation Assay}

CyQUANT $^{\mathrm{TM}}$ NF Cell Proliferation Assay Kit (Invitrogen, MA, USA) was used to examine the proliferative effect of AdipoRon in vitro. CyQuant ${ }^{\circledR}$ dye is a fluorochrome that intercalates with the nuclear DNA content in living cells (53). The emission intensity is correlated linearly with cell number over the range of 10 to 50,000 cells (53). One hundred microliters trypsinised subculture was seeded at a density of 0.02 million per well in the 96-well flat-bottom microplates (Falcon, Fisher Scientific, NH, USA) coated with $0.1 \%$ polyL-lysine (Sigma, MO, USA). The subculture was maintained in the drug-free culture medium for $24 \mathrm{~h}$. The next day, the medium was decanted and replaced by a new medium containing AdipoRon alone or with the inhibitors. Specifically, AdipoRon $(40 \mathrm{mg} / \mathrm{mL})$, GW9662 $(20 \mathrm{mg} / \mathrm{mL})$, and SR-18292 maleate $(20 \mathrm{mg} / \mathrm{mL})$ were dissolved in DMSO as stocks and then diluted with the culture medium. To examine the proliferative effect of AdipoRon, subculture was independently treated by AdipoRon $(0.5,1,5$, or $25 \mu \mathrm{M})$ for $4 \mathrm{~h}$ or $24 \mathrm{~h}$. To examine the involvement of PPAR- $\gamma$ and PGC- $1 \alpha$ in AdipoRon-induced cell proliferation, subculture was first pretreated by inhibitors PPAR- $\gamma$ blocker: GW9662 $(10 \mu \mathrm{M}$; APE $\times$ BIO, TX, USA) (54) and PGC- $1 \alpha$ blocker: SR-18292 (20 $\mathrm{MM}$; Sigma-Aldrich, MO, USA) (55) for $1 \mathrm{~h}$, followed by AdipoRon and inhibitor co-treatment for $24 \mathrm{~h}$. All control samples were treated with $2 \%$ DMSO $(v / v)$ as vehicle treatment. After treatments, culture media were decanted. One hundred microliters $1 \times$ CyQuant $₫ \mathrm{NF}$ dye was added to each well. One hour after, sample fluorescence (excitation/emission $\lambda=480 / 520 \mathrm{~nm}$ ) was measured using the Varioskan ${ }^{\mathrm{TM}}$ Flash Plate Reader (Thermo Fisher Scientific, MA, USA). Cell proliferation rate was determined by comparing emission intensity for a drug-treated subculture to DMSO-treated controls. The relative cell proliferation was calculated as follows: Cell proliferation $\%=\frac{\left(\mathrm{OD}_{\text {Sample }}-\mathrm{OD}_{\text {Blank }}\right)}{\left(\mathrm{OD}_{\text {Control }}-\mathrm{OD}_{\text {Blank }}\right)} \times 100 \%$, where readings of the cell-free well and untreated wells were the blank and the positive control, respectively.

\section{Statistical Analyses}

Data were shown as mean \pm SEM. A paired $t$-test was performed to compare the novel/familiar arm visit in the Y-maze task. To evaluate the effects of AdipoRon treatment and STZdiabetes, two-way ANOVA was employed in behavioural assessments, histological analyses, fEPSP analyses, and ELISA by Tukey post hoc test. Wilcoxon matched-pairs signed-rank test between AdipoRon- and vehicle-treated animals in the control and diabetic animals separately to address dendritic complexity. Two-way ANOVA with LSD post hoc test was applied in the densitometric analyses of immunoblotting. One-way ANOVA with LSD post hoc test was used to evaluate the AdipoRon dosage effect in in vitro proliferation assay. Statistical analyses were performed in Prism 8.0 software (GraphPad Software, USA). $P<0.05$ was considered statistically significant.

\section{Results}

\section{Chronic Treatment with AdipoRon Mimicked Voluntary Running to Ameliorate Diabetes-Impaired Spatial Memory}

Hippocampal-dependent spatial recognition memory was assessed by a Y-maze test (56). Control mice with an intact 
spatial recognition memory showed a significantly higher exploration ratio in the novel arm (Fig. 1B and Appendix Table S1; $P<0.0005$ vs. Novel arm). The STZ-diabetic mice showed a greater preference towards the familiar arm (Fig. $1 \mathrm{~B} ; P=0.0140$ vs. Novel arm), suggesting spatial memory deficit in diabetic mice. Two-way ANOVA revealed significant main effects of treatments (effect of interaction: $F_{2,36}=$ 21.01, $P<0.0001$; effect of STZ: $F_{1,36}=0.97, P=0.331$; effect of treatment: $\left.F_{2,36}=23.99, P<0.0001\right)$. AdipoRon treatment (Fig. 1C and Appendix Table S2; $P<0.0001$ vs. STZ-Vehicle) mimicked the effect of voluntary running (Fig. $1 \mathrm{C} ; P<0.0001$ vs. STZ-Vehicle) on restoring spatial memory deficits.

Diabetic mice had a shorter time spent at the centre in the open field (Fig. 1D; $P<0.005$ vs. Control-Vehicle), indicating an increased in anxiety-like behaviour (effect of interaction: $F_{2,36}=2.998, P=0.0625$; effect of STZ: $F_{1,36}=10.09, P=$ 0.0031; effect of treatment: $F_{2,36}=15.75, P<0.0001$ ). Voluntary running elicited anxiolytic effect on diabetic animals since diabetic runners spent significantly more time in the centre of the open field (Fig. 1D; $P=0.0001$ vs. STZVehicle). The anxiolytic effect was not observed in AdipoRon-treated diabetic mice (Fig. 1D; $P=0.133$ vs. STZ-Vehicle). Neither running (Fig. 1E; $P>0.99$ vs. STZVehicle) nor AdipoRon treatment (Fig. $1 \mathrm{E} ; P=0.895$ vs. STZ-Vehicle) affected locomotor activity.

\section{AdipoRon Treatment Resembles Voluntary Running on Restoring Hippocampal Adult Neurogenesis in Diabetic Mice}

We have previously shown that voluntary running restored adult neurogenesis in STZ-diabetic mice (30). Here we sought to determine whether AdipoRon treatment could mimic the effect of voluntary running on promoting adult hippocampal neurogenesis. AdipoRon treatment showed similar effect to voluntary running on promoting cell proliferation (Fig. 2A and $\mathrm{E} ; P=0.0004$ vs. Control-Vehicle), but not survival (Fig. $2 \mathrm{C}$ and $\mathrm{G} ; P=0.99$ vs. Control-Vehicle) or differentiation (Fig. $2 \mathrm{D}$ and $\mathrm{H} ; P=0.99$ vs. Control-Vehicle) of newborn neurons in the control mice. Voluntary wheel running significantly increased the density of immature neuron (Fig. 2B and F; $P=0.0002$ vs. Control-Vehicle) and neuronal differentiation (Fig. 2D; $P=0.0414$ vs. ControlVehicle) in control mice. In diabetic mice, AdipoRon treatment mimicked the effect of voluntary running on restoring proliferating cells (Figs. 2A and S2A; $P=0.0063$ vs. STZVehicle), immature neurons (Figs. $2 \mathrm{~B}$ and $\mathrm{S} 2 \mathrm{~B} ; P<0.0005$ vs. STZ-Vehicle), and promoting neuronal differentiation (Figs. 2D and S2D; $P=0.0034$ vs. STZ-Vehicle), but not cell survival (Figs. 2C and S2C; $P=0.99$ vs. STZVehicle).

\section{Involvement of PPAR- $\gamma / P G C-1 a$ Signalling in the Proliferative Effect of AdipoRon In Vitro}

Adiponectin significantly enhances cell proliferation in cultured N2a cells (34). We, therefore, examined whether AdipoRon treatment exerts a direct effect on promoting cell proliferation using $\mathrm{N} 2 \mathrm{a}$ cell culture. Here we showed that an acute and dose-specific effect of AdipoRon $(1 \mu \mathrm{M}, 4$-h incubation) on promoting cell proliferation (Fig. 2I; $P<0.05$ vs. $0 \mu \mathrm{M}$ AdipoRon). However, prolonged incubation ( $24 \mathrm{~h})$ at all AdipoRon dosages ranging from 0.5 to $25 \mu \mathrm{M}$ promoted cell proliferation (Fig. $2 \mathrm{I} ; P<0.05$ vs. $24 \mathrm{~h}: 0 \mu \mathrm{M}$ AdipoRon), suggesting a time-dependent effect of AdipoRon on promoting cell proliferation.

The AMPK/PPAR- $\gamma /$ PGC- $1 \alpha$ signalling pathway is involved in the anti-obesity effects of adiponectin $(57,58)$, while both adiponectin $(34,59-61)$ and physical exercise $(34,36)$ activate the AMPK signalling pathway. Therefore, we further examined whether AdipoRon treatment promotes cell proliferation via activating AMPK/PPAR- $\gamma /$ PGC- $1 \alpha$ signalling in vitro. The results indicated that treatment with PGC- $1 \alpha$ inhibitor SR-18292 or PPAR- $\gamma$ inhibitor GW9662 alone, or together, significantly inhibited the proliferative effect of AdipoRon on cell proliferation (Fig. $2 \mathrm{~J} ; P<0.005$ vs. Control). The data suggest that PPAR- $\gamma /$ PGC- $1 \alpha$ signalling is critical for AdipoRon to promote cell proliferation.

\section{AdipoRon Treatment Ameliorated Impairments in Dendritic Arborisation and Spine Loss in Diabetic Mice}

Structural changes in dendritic arborization could also affect hippocampal function; and hence hippocampal-dependent learning and memory $(45,62,63)$. Voluntary running exercise significantly promotes dendritic enrichment in the hippocampus $(18,45,64)$. The Golgi-stained neurons in diabetic mice showed significant reductions in total dendritic length in both younger (Fig. 3A; $P=0.0434$ vs. Control-Vehicle) and mature granule neurons (Fig. 3D; $P=0.0014$ vs. Control-Vehicle). Sholl analysis revealed that AdipoRon treatment enhanced dendritic complexity in diabetic mice (Figs. 3B and S3A; $P$ $=0.0012$ vs. STZ-Vehicle and Figs. 3E and S3B; $P=0.0003$ vs. STZ-Vehicle). Neither STZ (Fig. $3 C ; P=0.2215$ vs. Control-Vehicle) nor AdipoRon (Fig. 3C; $P=0.323$ vs. Control-Vehicle) affected soma size in younger granule neurons. Two-way ANOVA revealed a significant main effect of diabetes on soma size in mature granule cells (Fig. 3F; effect of interaction: $F_{1,16}=2.251, P=0.153$; effect of STZ-diabetes: $F_{1,16}=15.64, P=0.0011$; effect of treatment: $F_{1,16}=$ 12.97, $P=0.0024$ ). AdipoRon significantly restored soma size in mature granule cells in diabetic mice (Fig. 3F; $P=$ 0.0114 vs. STZ-Vehicle). Similarly, two-way ANOVA revealed significant main effects of AdipoRon and diabetes on 
A

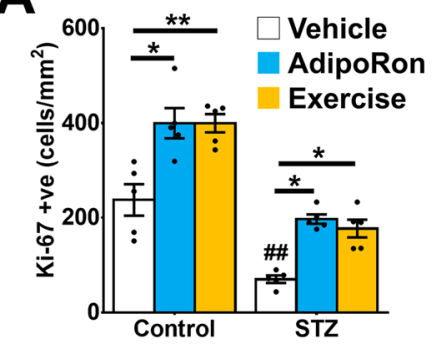

B

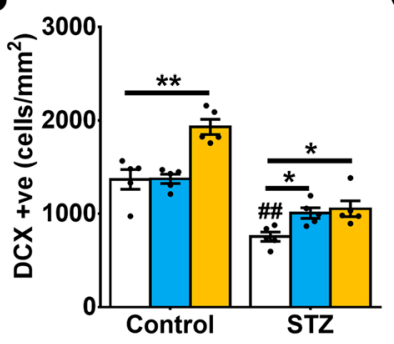

C

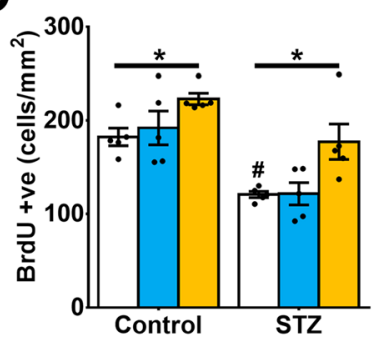

D

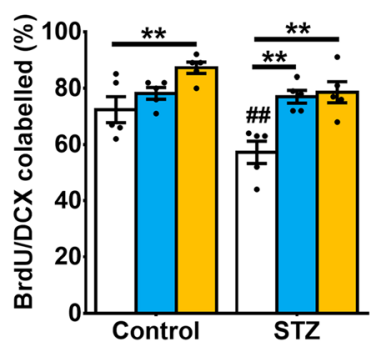

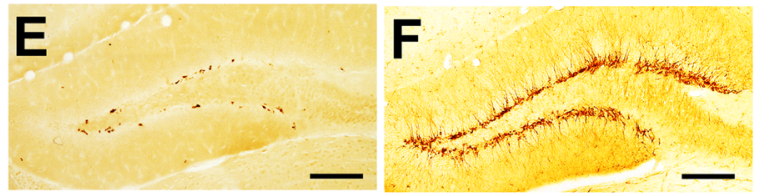
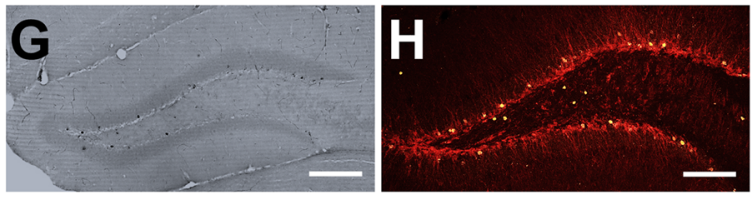

I
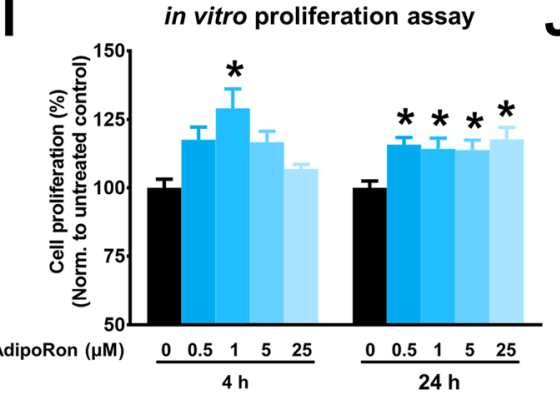

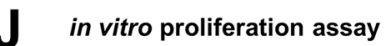

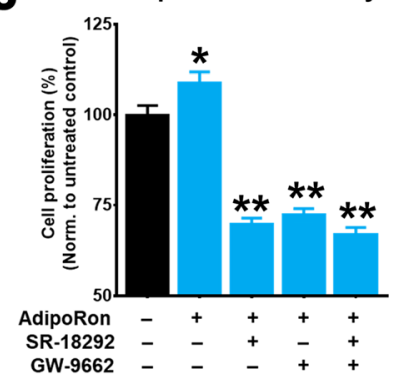

Fig. 2 AdipoRon treatment mimicked the effect of physical exercise in restoring adult hippocampal neurogenesis in diabetic mice. A STZdiabetes reduced number of Ki- $67^{+}$proliferating cell (Tukey's post hoc test: ${ }^{\# \#} P<0.005$ vs. Control-Vehicle). AdipoRon treatment (Tukey's post hoc test: $* P<0.05$ vs. Control-Vehicle; $* P<0.05$ vs. STZ-Vehicle) mimicked the effect of exercise (Tukey's post hoc test: $* * P<0.005$ vs. Control-Vehicle; $* P<0.05$ vs. STZ-Vehicle) on increasing proliferating cell in both control and diabetic mice. $n=5$ per group. Previously reported Control-Vehicle and Control-AdipoRon data were used to support this study (44). B STZ-diabetes reduced the density of $\mathrm{DCX}^{+}$immature neuron (Tukey's post hoc test: ${ }^{\# \#} P<0.005$ vs. Control-Vehicle). AdipoRon treatment (Tukey's post hoc test: $* * P<0.005$ vs. STZ-Vehicle) restored the density of immature neurons as running did in diabetic mice (Tukey's post hoc test: $* * P<0.005$ vs. STZ-Vehicle), but not increasing the immature neuron density in control mice (Tukey's post hoc test: $* P>0.05$ vs. Control-Vehicle). Previously reported Control-Vehicle and ControlAdipoRon data were used to support this study (44). C STZ reduced cell survival in the DG (Tukey's post hoc test: ${ }^{\#} P<0.05$ vs. Control-Vehicle) marked by BrdU. Voluntary running increased cell survival in both control (Tukey's post hoc test: $* P<0.05$ vs. Control-Vehicle) and diabetic animals (Tukey's post hoc test: $* P<0.05$ vs. STZ-Vehicle). However, AdipoRon treatment showed no significant effects (Tukey's post hoc test: $* P>0.05$ vs. STZ-Vehicle). Previously reported Control-Vehicle and Control-AdipoRon data were used to support this study (44). D STZ impaired neuronal differentiation (Tukey's post hoc test: ${ }^{\#} P<0.05$ vs.
Control-Vehicle) with reduced percentages of BrdU/DCX co-labelling. AdipoRon treatment (Tukey's post hoc test: $* * P<0.005$ vs. STZVehicle) restored neuronal differentiation of new-born cells in diabetic mice (Tukey's post hoc test: ${ }^{\#} P<0.05$ vs. Control-Vehicle), as runners did. However, AdipoRon did not show effects on neuronal differentiation in healthy control mice ( $n=5$ animals per group). Previously reported Control-Vehicle and Control-AdipoRon data were used to support this study (44). $\mathbf{E}-\mathbf{H}$ Representative image of $\mathbf{E}$ proliferating progenitor cell, marked by $\mathrm{Ki}-67$, in the subgranular zone. $\mathbf{F}$ Representative image of immature neurons, marked by doublecortin (DCX). G New-born cell (3 days before treatment until day of sacrifice), marked by BrdU, in DG. $\mathbf{H}$ Representative image of BrdU/DCX co-labelled cells, representing the new-born cells committing the neuronal lineage. I In vitro study of the direct effect of AdipoRon on cell proliferation in culture N2a cells. AdipoRon exerted proliferating effect in a time- and dose-dependent manner ( 6 replicates per independent experiment; $n=3$ independent experiments/treatment group) in CyQuant assay (LSD post hoc test: $* P$ $<0.05$ vs. Control). $\mathbf{J}$ In vitro examination of the involvement of PPAR$\gamma /$ PGC- $1 \alpha$ signalling in AdipoRon-induced cell proliferation in culture N2a cells. AdipoRon-induced cell proliferation was mediated by PPAR$\gamma /$ PGC- $1 \alpha$ signalling. Blocking either PPAR- $\gamma$ by SR- 18292 or PGC- $1 \alpha$ by GW9662 or co-treatment diminished AdipoRon-induced cell proliferation (9 replicates per independent experiment; $n=4$ independent experiments/group) (LSD post hoc test: $* P<0.05$ vs. untreated control) spine density in mature granule cells (Fig. 3G; effect of interaction: $F_{1,16}=5.826, P=0.0281$; effect of STZ: $F_{1,16}=48.04$, $P<0.0001$; effect of treatment: $F_{1,16}=106.3, P<0.0001$ ). Diabetes reduced spine density in mature granule cells (Figs. $3 \mathrm{H}$ and S4B; $P<0.0001$ vs. Control-Vehicle) but not the younger neurons (Figs. 3G and S4A; $P=0.124$ vs. ControlVehicle). Notably, AdipoRon treatment increased spine density in mature granule neurons of both control and diabetic mice (Fig. 3H-I; Control-AdipoRon: $P=0.0002$ vs. Control-Vehicle and STZ-AdipoRon: $P<0.0001$ vs. STZVehicle).

\section{AdipoRon-Restored LTP Deficits in the Hippocampal DG of Diabetic Mice}

Previous studies have shown that long-term voluntary wheel running exercise (2 to 3 months) promotes hippocampal synaptic plasticity $(62,65)$. To determine whether AdipoRon promotes synaptic plasticity as exercise does, we examined its effect on LTP formation in the hippocampal DG of diabetic mice (Fig. 4A). Diabetes significantly impaired LTP formation (Fig. 4C; $P<0.0001$ vs. Control-Vehicle), which was restored by bath application with AdipoRon (10 min; 0.5 

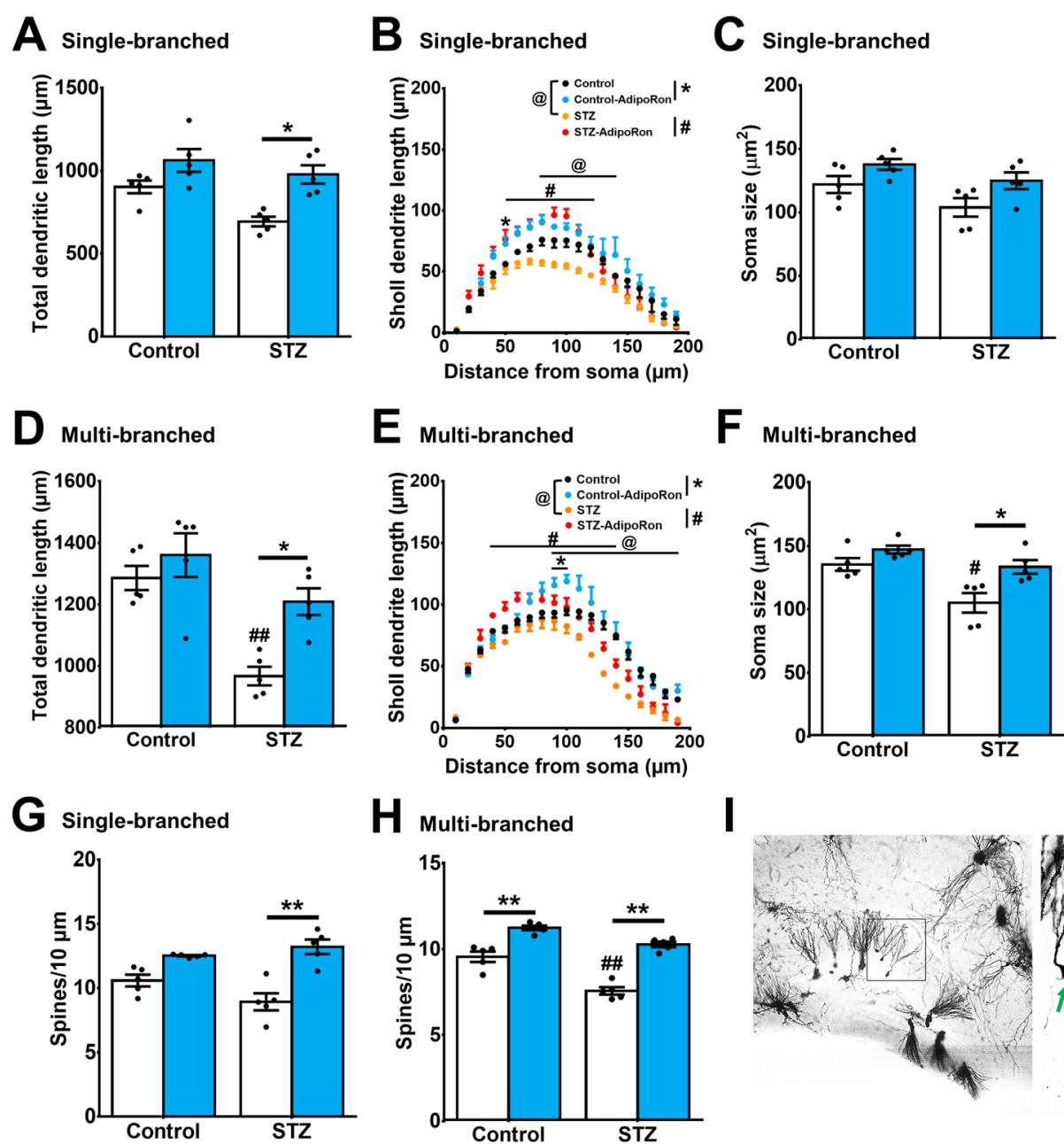

F Multi-branched

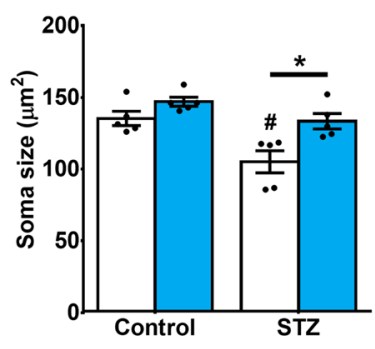

I

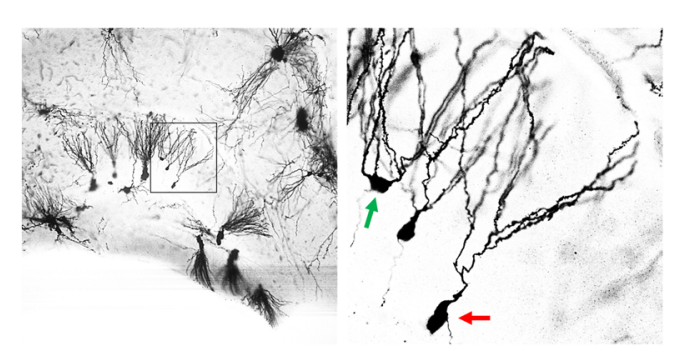

Fig. 3 AdipoRon restored dendritic arborisation, soma size, and spine density of dentate granule cells in diabetic mice. A, B In granule cells with single primary dendrite, STZ reduced $\mathbf{A}$ total dendritic length (Tukey's post hoc test: ${ }^{\#} P<0.05$ vs. Control-Vehicle) and $\mathbf{B}$ dendritic arborisation in diabetic mice (Tukey's post hoc test: ${ }^{\#} P<0.05$ vs. STZVehicle), which could be restored by AdipoRon treatment (Tukey's post hoc test: $* P<0.05$ vs. STZ-Vehicle). C Diabetic condition and AdipoRon treatment did not alter soma size in single-branched neurons. D, E: D In granule cells with multiple primary dendrites, STZ reduced total dendritic length (Tukey's post hoc test: ${ }^{\# \#} P<0.005$ vs. ControlVehicle). Meanwhile, AdipoRon treatment restored total dendritic length (Tukey's post hoc test: $* P<0.05$ vs. STZ-Vehicle) and $\mathbf{E}$ promoted dendritic arborisation in diabetic mice (Tukey's post hoc test: ${ }^{\#} P<0.05$ vs. STZ-Vehicle), whereas AdipoRon restored the dendritic length (Tukey's post hoc test: $* P<0.05$ vs. STZ-Vehicle). F AdipoRon

treatment restored reduction in soma size in diabetic mice (Tukey's post hoc test: ${ }^{\#} P<0.05$ vs. Control-Vehicle, ${ }^{*} P<0.05$ ), but AdipoRon did not affect soma size in multiple-branched neurons of control mice. $\mathbf{G}$ AdipoRon treatment increased spine density in the granule cells with single primary dendrite in diabetic mice (Tukey's post hoc test: $* * P<$ 0.005 vs. STZ-Vehicle). H Diabetes reduced spine density in granule neurons with multiple primary dendrites (Tukey's post hoc test: ${ }^{\# \#} P<$ 0.005 vs. Control-Vehicle), which could be restored by AdipoRon treatment in both control and diabetic mice (Tukey's post hoc test: $* * P<$ 0.005). $n=5$ animals per group. I Representative Golgi staining of the hippocampal dentate gyrus, with green arrow marking the multiplebranched (more mature) neuron at the outer granule cell layer, and the red arrow marking a single-branched (late-born) neuron at the inner granule cell layer

$\mu \mathrm{M})$ (Fig. 4C; $P<0.0001$ vs. STZ). Two-way ANOVA revealed significant effects of AdipoRon and diabetic on LTP formation (Fig. 4B and C: Effect of STZ-diabetic: $F_{1,40}=$ 26.25, $P<0.0001$; effect of AdipoRon: $F_{1,40}=23.08, P<$ 0.0001; effect of interaction: $\left.F_{1,40}=12.69, P=0.001\right)$. PGC$1 \alpha$ is a master regulator of mitochondrial biogenesis $(66,67)$ which is necessary for LTP formation (68). As expected, pharmacological inhibition of PGC- $1 \alpha$ by SR-18292 (Fig. 4D) diminished the promoting effect AdipoRon on LTP formation in diabetic mice (Fig. 4E \& 4F; $P=0.514$ vs. STZAdipoRon). Bath application with NMDA receptor subunit blockers, including NVP-AAM077 (GluN2A inhibitor) or Ro 25-6981 (GluN2B inhibitor) (Fig. 4G), showed similar effects (Fig. 4H and I; GluN2A: $P<0.0188$ vs. STZAdipoRon; GluN2B: $P<0.011$ vs. STZ-AdipoRon). Oneway ANOVA revealed significant effects of pharmacological inhibitions of NMDAR subunits on LTP formation $\left(F_{2,27}=\right.$ $6.133, P=0.0064)$. Altogether, the findings demonstrated the 

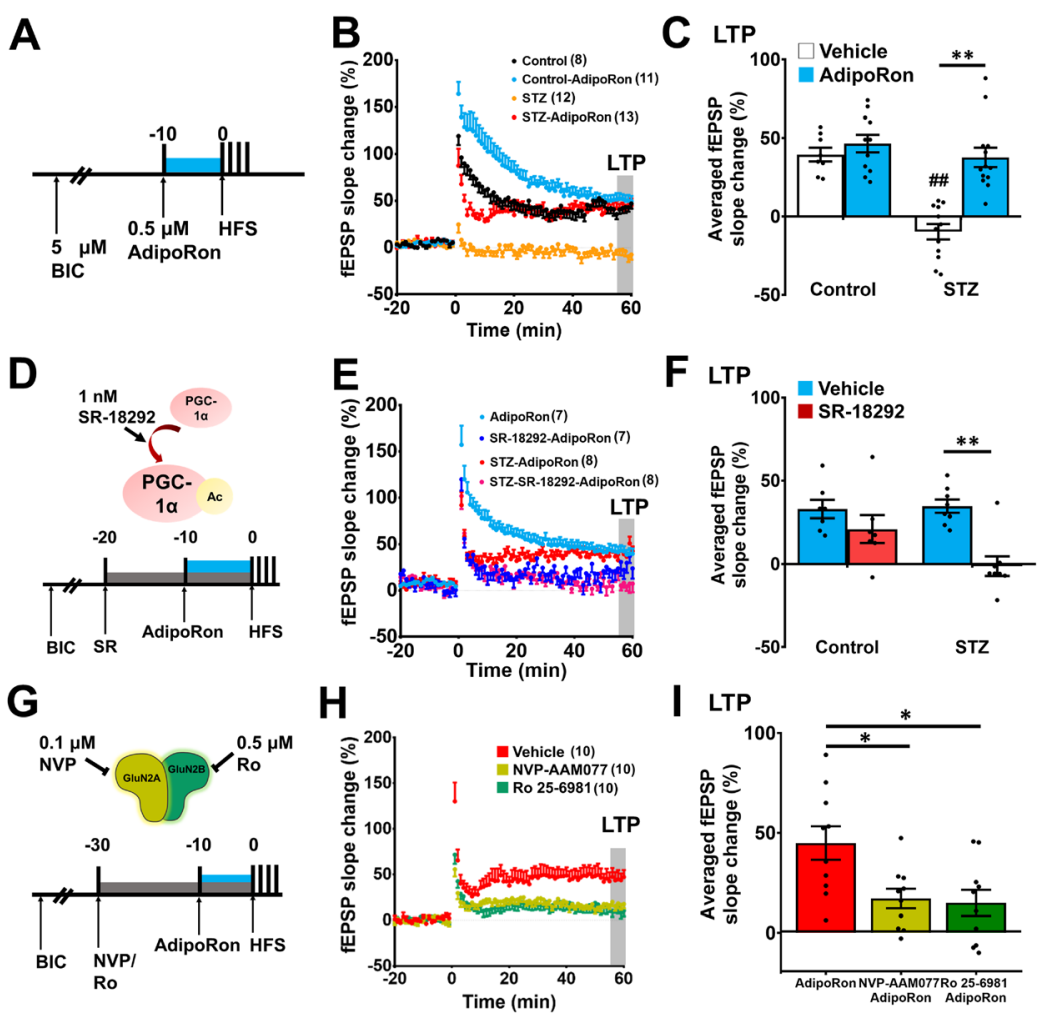

Fig. 4 AdipoRon treatment restored NMDA receptor-dependent LTP deficit in diabetic mice depending on PGC- $1 \alpha$ signalling. A LTP induction using HFS protocol to examine the effect of AdipoRon on synaptic plasticity in the hippocampal dentate gyrus. B Effect of AdipoRon on field excitatory postsynaptic potential (fEPSP) in control and diabetic brain slices. $\mathbf{C}$ The averaged fEPSP slope change of the last $5 \mathrm{~min}$. Brain slice from diabetic mice showed deficit in LTP formation, which was rescued by $0.5 \mu \mathrm{M}$ AdipoRon (Control: $n=8$ slices; ControlAdipoRon: $n=11$ slices; STZ: $n=12$ slices; STZ-AdipoRon: $n=13$ slices; Tukey's post hoc test: $* P<0.005$ Vehicle vs. AdipoRon; $* * P<$ 0.005 between Vehicle vs. AdipoRon; \#\#P<0.005 Control vs. STZ). D Experimental protocol of PGC- $1 \alpha$ inhibition. E, F: E Effect of PGC- $1 \alpha$ inhibition on AdipoRon-elicited field excitatory postsynaptic potential. F

involvement of PGC- $1 \alpha$ and NMDA receptor subunits GluN2A and GluN2B in the action of AdipoRon on restoring synaptic plasticity in diabetic mice.

\section{AdipoRon Treatment Promoted BDNF Levels and Activated AMPK/PGC-1a Signalling in the Hippocampal DG}

Voluntary running exercise elevates adiponectin levels in the whole hippocampus but not in the serum of healthy mice (69). Our results showed that AdipoRon treatment restored serum adiponectin levels in diabetic mice (Fig. 5A; STZ-AdipoRon: $P=0.0434$ vs. STZ-Vehicle) resembling the effect of voluntary wheel running (Fig. 5A; STZ-Exercise: $P=0.011$ vs. STZ-Vehicle). However, AdipoRon treatment did not restore the decrease in adiponectin level in the DG of diabetic mice (Fig. 5B; $P=0.994$ vs. STZ-Vehicle) and reduced adiponectin
The average fEPSP slope change of the last 5 min where inhibition of PGC- $1 \alpha$ significantly impaired LTP formation (Tukey's post hoc test: $* * P<0.005$ between Vehicle vs. SR-18292 under STZ condition). $n=$ 7 slice per control group and $n=8$ slices per STZ-diabetic group. G Experimental protocol for investigating the involvements of NMDA receptor subunits (GluN2A and GluN2B) in AdipoRon-induced LTP in diabetic slices. H, I: $\mathbf{H}$ Inhibition of GluN2A or GluN2B diminished AdipoRon-restored field excitatory postsynaptic potential in diabetic brain slices. I The average fEPSP slope change of the last $5 \mathrm{~min}$ where inhibition of GluN2A or GluN2B diminished LTP formation $(n=10$ slices per treatment group; Tukey's post hoc test: $* P<0.05$ NVPAAM077 or Ro-25-6981 vs. Vehicle)

levels in the control mice (Fig. 5B; $P<0.0001$ vs. ControlVehicle).

BDNF is a critical neurotrophin required for physical exercise to induce hippocampal neurogenesis. We examined whether AdipoRon enhances BDNF levels and AMPK/ PGC- $1 \alpha$ signalling that is also be activated by physical exercise $(34,39,70)$. AdipoRon and exercise treatment elevated BDNF levels in the control mice (Fig. 5C; Control-AdipoRon: $P<.0001$ and Control-Exercise: $P<0.0001$ vs. ControlVehicle). Diabetic condition reduced serum BDNF levels (Fig. 5C; STZ-Vehicle $P<0.0001$ vs. Control-Vehicle). AdipoRon and voluntary running restored serum BDNF levels in diabetic mice (Fig. 5C; STZ-AdipoRon: $P=0.0039$ and STZ-Exercise: $P=0.0098$ vs. STZ-Vehicle). Apart from the elevated serum BDNF levels following AdipoRon treatment, BDNF levels in the hippocampal DG were increased, though diabetes did not alter BDNF levels in the dentate region (Fig. 5D; $P=0.743$ vs. Control-Vehicle). Conversely 
AdipoRon treatment promoted BDNF levels in the DG of diabetic (Fig. 5D; $P=0.0039$ vs. STZ-Vehicle) and control mice (Fig. 5D; $P<0.0001$ vs. Control-Vehicle). These findings implicated that increased BDNF levels could be linked to the promoting effect of AdipoRon on hippocampal neuroplasticity.

We have previously shown that adiponectin mediates physical exercise-induced adult hippocampal neurogenesis through AdipoR1/AMP-activated protein kinase (AMPK). Besides, AMPK and PPAR- $\gamma$ coactivator $1-\alpha$ (PGC- $1 \alpha)$ are potential upstream transducers of BDNF; therefore, we further tested whether AdipoRon elicited its effect via the AMPK/ PGC-1 $\alpha$ pathway (Fig. 5E). Western blot analysis showed that AdipoRon treatment enhanced the phosphorylation of $\mathrm{AMPK}^{\mathrm{Thr} 172}$ (Fig. 5F) in both diabetic and control mice. AdipoRon treatment also activated PGC- $1 \alpha$ in diabetic and control mice, as indicated by reducing the inhibitory form of PGC- $1 \alpha^{\text {Ser571 }}$ (Fig. 5G). In sum, the results suggested that AdipoRon treatment significantly increased AMPK and PGC- $1 \alpha$ activity and BDNF levels in the DG.

\section{Discussion}

This study demonstrates that AdipoRon treatment elicits procognitive and neurotrophic effects indicating its potential in acting as an exercise mimetic. Here we demonstrated that AdipoRon treatment rescued spatial memory deficits in diabetic mice in a manner that was reminiscent of the procognitive effects observed with voluntary running exercise (see also Appendix Tables S1 and S2). AdipoRon also rescued adult hippocampal neurogenesis, increased dendritic arborisation and spine density, enhanced hippocampal LTP, and increased serum and hippocampal DG levels of BDNF in diabetic mice.

The antidiabetic effects of AdipoRon were first demonstrated in high-fat diet-fed mice and leptin-deficient $(d b / d b)$ mice (42). In this study, we used a diabetic mouse model presenting more pronounced cognitive impairments to examine the therapeutic effects of AdipoRon for cognition. We have previously reported that streptozotocin-induced diabetes impairs adult hippocampal neurogenesis (30). Our results
A

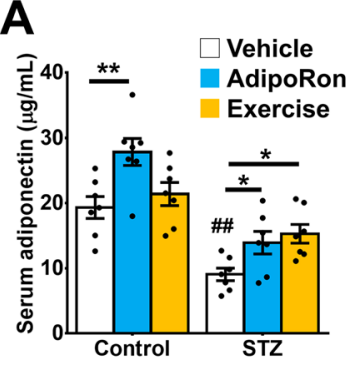

B

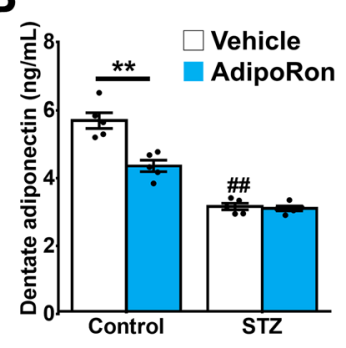

C

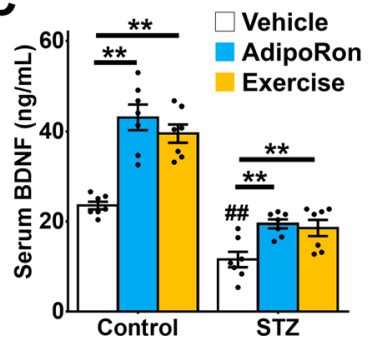

D

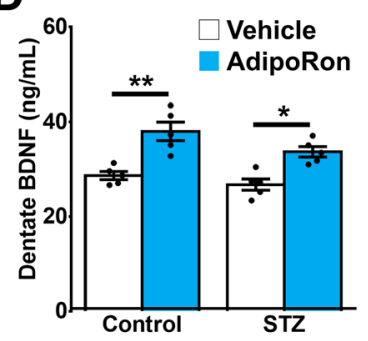

E
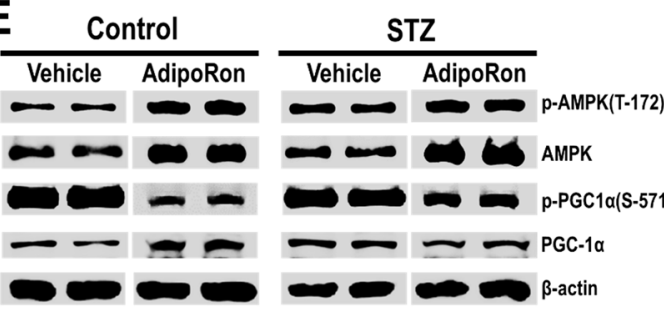

F
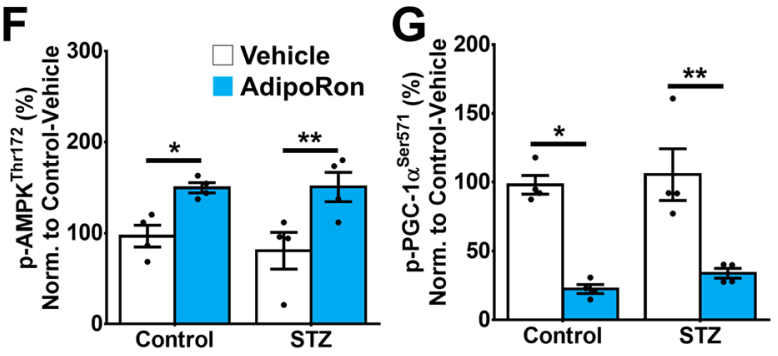

Fig. 5 Effects of AdipoRon treatment on expression levels of adiponectin, BDNF, and activation of AMPK and PGC- $1 \alpha$ signalling. A STZ-diabetes reduced serum adiponectin levels (Tukey's post hoc test: ${ }^{\# \#} P<0.005$ vs. Control-Vehicle). AdipoRon treatment restored serum adiponectin levels in diabetic mice, as voluntary running did (Tukey's post hoc test: $* P<0.05$ vs. STZ-Vehicle). AdipoRon treatment increased serum adiponectin levels in control mice (Tukey's post hoc test: $* * P<$ 0.005 vs. Control-Vehicle) while exercise could not (Tukey's post hoc test: $P>0.05$ vs. Control-Vehicle). $n=7$ per group. Previously reported Control-Vehicle and Control-AdipoRon data were used to support this study (44). B Diabetes significantly reduced adiponectin level in DG (Tukey's post hoc test: ${ }^{\# \#} P<0.005$ vs. Control-Vehicle), whereas AdipoRon treatment reduced adiponectin levels in control (Tukey's post hoc test: $* * P<0.005$ vs. Control-Vehicle). AdipoRon treatment did not restore adiponectin levels in DG from diabetic mice. $n=5$ replicates. $\mathbf{C}$ Diabetes reduced serum BDNF levels (Tukey's post hoc test: ${ }^{\# \#} P<0.005$ vs. Control-Vehicle). AdipoRon and exercise treatment increased serum

BDNF levels in control animals (Tukey's post hoc test: $* * P<0.005$ vs. Control-Vehicle), while both treatments restored serum BNDF levels in diabetic mice (Tukey's post hoc test: $* * P<0.005$ vs. STZ-Vehicle). $n=7$ per group. Previously reported Control-Vehicle and Control-AdipoRon data were used to support this study (44). D Diabetes did not alter BDNF level in DG, whereas AdipoRon treatment increased BDNF levels in control (Tukey's post hoc test: $* * P<0.005$ vs. Control-Vehicle) and diabetic mice (Tukey's post hoc test: $* P<0.05$ vs. STZ-Vehicle). $n=5$ replicates. E Representative images of western blot analysis. $(n=4$ technical replicates from 7 pairs of DG pooled-sample/group). F AdipoRon treatment also increased $\mathrm{p}$-AMPK $\alpha^{\text {Thr172 }}$ expression in the hippocampal DG (LSD post hoc test: $* P<0.05$ vs. Control-Vehicle). G AdipoRon treatment significantly suppressed the expressions of p-PGC-1 $\alpha^{\text {Ser571 }}$, a phosphorylated inhibitory form of PGC- $1 \alpha$, in the DG of control (LSD post hoc test: $* P<0.05$ vs. Control-Vehicle) and diabetic mice (LSD post hoc test: $* * P<0.05$ vs. STZ-Vehicle) 
support a prior study that a single injection of streptozotocin (65 mg/kg i.v.) can induce hippocampal atrophy, spine loss, and hippocampal-dependent spatial learning and memory impairment (71).

Physical exercise facilitates learning and memory formation, enhances adult hippocampal neurogenesis, increases dendritic arborisation, and improves hippocampal synaptic plasticity (72-76). In addition to promoting adult hippocampal neurogenesis (33) and learning and memory performance (32), adiponectin can mediate the effects of physical exercise on reducing depression and promoting hippocampal cell proliferation $(30,34)$. In the current study, we showed that the adiponectin receptor agonist, AdipoRon, could similarly restore hippocampal cell proliferation, BDNF levels, and memory performance in diabetic mice $(34,62)$. Furthermore, AdipoRon treatment restored dendritic atrophy and spine density in DG granule cells of the diabetic mice. Adiponectin has shown to be indispensable for dendritic and spine formation in the DG granule neurons (33). Our results showed that AdipoRon treatment promoted dendritic complexities and spine densities in the dentate granule neurons associated with the increased serum and dentate BDNF levels, whereas diabetic mice showed a significant reduction in serum and dentate adiponectin levels. AD mice show decreased adiponectin levels and spine density in the cortex and hippocampus, which could be restored by AdipoRon treatment (31). Our results collectively suggest that AdipoRon treatment resembles the pro-cognitive and neurotrophic effects of voluntary running and could be an effective treatment for restoring structural plasticity and improving learning and memory associated with diabetes.

Both adiponectin and AdipoRon can cross the blood-brain barrier $(31,34)$. To examine the direct effect of AdipoRon, we showed that AdipoRon, like adiponectin, can elicit direct proliferative effects in the N2a cultured cell, where adiponectin receptors are expressed (34). The current results have demonstrated the direct effect of AdipoRon on restoring LTP formation in the dentate region in diabetic mice. It is known that adiponectin modulates LTP formation in the hippocampal CA1 (8) and CA3 (32) regions, whereas AdipoRon can restore LTP deficits induced by adiponectin deficiency (32). Our findings indicated the significant effect of AdipoRon on restoring synaptic deficits in the hippocampus, a brain region with AdipoR1 and AdipoR2 being expressed (32). NMDA receptor (NMDAR) subunits, such as GluN2A and GluN2B, mediate the LTP induction in the hippocampus $(77,78)$, while adiponectin deficiency reduces the expressions of the $\alpha$ amino-hydroxy-methyl-isoxazolepropionic acid receptor (AMPAR) and NMDAR subunits in the hippocampus (79). The expressions of AMPAR and NMDAR subunits and adiponectin receptors are increased in post-recording $5 \times$ FAD hippocampal slices (80). The present study also addressed the critical roles of GluN2A/B in AdipoRon-induced
LTP formation in hippocampal slices from diabetic mice, suggesting the involvement of NMDA receptors in AdipoRoninduced synaptic plasticity in the hippocampus.

AdipoRon might exert indirect action on promoting hippocampal plasticity because serum adiponectin levels in diabetes were increased by AdipoRon treatment. Adiponectin levels in the DG were markedly reduced in diabetic mice, and AdipoRon treatment failed to restore the decrease. Besides, AdipoRon treatment reduced adiponectin levels in the DG in physiological condition. A feedback mechanism may be involved in downregulating the adiponectin levels in the brain in response to the AdipoRon action on activating central adiponectin signalling. In contrast, excessive adiponectin in the brain or hyperactivation of the adiponectin signalling pathway may impair neural plasticity. Another possibility is that AdipoRon may increase the expression levels of adiponectin receptors in the hippocampal DG. Therefore, the reduction in adiponectin levels serves as a negative feedback regulation to avoid over-activation of adiponectin signalling. Lastly, adiponectin receptors are expressed on endothelial cells of the blood-brain barrier (BBB) (81), and adiponectin signalling maintains the BBB integrity (82). AdipoRon administration and elevated circulating adiponectin may alter the BBB permeability, limiting the entry of adiponectin to the brain from the circulation.

Elevated BDNF levels promote adult neurogenesis (83) and synaptic plasticity (84), which in turn facilitate learning and memory formation (85). Our findings demonstrated that enhancement in structural and synaptic plasticity is associated with elevated dentate and serum BDNF levels following AdipoRon treatment. The central BDNF levels are known to be positively correlated with peripheral BDNF levels (86). Physical exercise promotes hippocampal BDNF levels through PGC-1 $\alpha$ signalling (39). Over-expression of PGC$1 \alpha$ restores BDNF levels in $\mathrm{A} \beta$-treated N2a cells (87). We have previously shown that adiponectin is required for exercise to induce AMPK activation in the hippocampus (34); however, administration of AdipoRon activated AMPK/ PGC- $1 \alpha$ signalling without increasing adiponectin levels in diabetic mice, suggesting a direct action of AdipoRon on activating adiponectin receptors and thus its downstream signalling cascade. The beneficial effects of AdipoRon on restoring hippocampal neuroplasticity could be linked to the activation of AMPK/PGC- $1 \alpha$ signalling pathway (Fig. 6). Our study reported that AdipoRon treatment enhances PGC- $1 \alpha$ activity in the DG. The in vitro proliferative assay has suggested the involvement of PGC- $1 \alpha /$ PPAR- $\gamma$ in the AdipoRon-induced cell proliferation and the involvement of PGC- $1 \alpha$ in the AdipoRon-induced LTP formation in diabetic mice. PGC$1 \alpha$ mediates the AMPK-induced neuronal growth and maturation (88). PGC- $1 \alpha$ is also essential for spine formation (40) and is a master regulator of mitochondrial biogenesis (66). Mitochondrial $\mathrm{Ca}^{2+}$ uptake is involved in LTP formation in 
Fig. 6 Summary of the effects of AdipoRon on promoting hippocampal neuroplasticity. Two weeks of AdipoRon treatment significantly promoted cell proliferation and neuronal differentiation in the dentate region. AdipoRon restored diabetes-induced impairment in adult hippocampal neurogenesis, dendritic complexity, and spine density, as well as NMDA receptor-dependent synaptic plasticity, through activating AMPK/PGC- $1 \alpha /$ BDNF signalling in the hippocampus. Graphical images are created in BioRender@

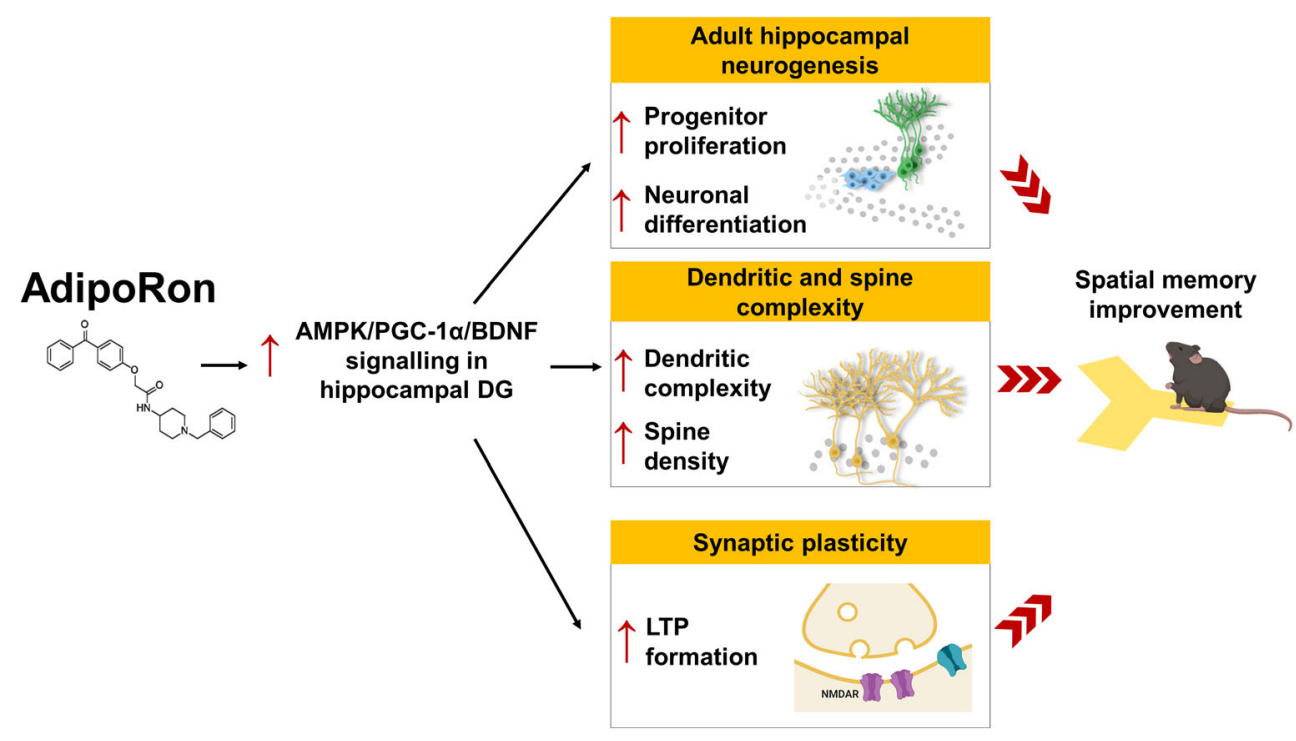

the hippocampus (68). It is possible that AdipoRon could activate PGC- $1 \alpha$ activity to promote mitochondrial biogenesis, which in turn promotes $\mathrm{Ca}^{2+}$ influx; and facilitates LTP formation.

Furthermore, AMPK is a master regulator of metabolism (89) and is necessary for maintaining neural stem cell proliferation (90). Voluntary running promotes hippocampal AMPK activation (40), which is absent in adiponectin knockout mice (34). Conversely, adiponectin deficiency reduces hippocampal AMPK activation (32). Activating AMPK activity leads to increased BDNF levels in a dose-dependent manner (91). We reported that AdipoRon treatment increased the serum adiponectin levels, but not in the dentate gyrus in diabetic mice, suggesting the activation of AMPK in the dentate region could be a direct effect of AdipoRon. Taken together, our results have suggested the involvement of AMPK/PGC$1 \alpha /$ BDNF signalling in the action of AdipoRon on rescuing hippocampal atrophy in diabetic mice.

\section{Conclusion}

Our results demonstrated that chronic treatment with AdipoRon mimicked the beneficial effects of physical exercise on promoting hippocampal-dependent learning and memory function and restoring adult neurogenesis in diabetic condition. In addition, AdipoRon treatment promoted dendritic complexity and synaptic plasticity as well as serum and dentate BDNF levels in the hippocampus of diabetic mice. The beneficial effects could be dependent on downstream AMPK/ PGC-1 $\alpha$ signalling. An adiponectin-based therapeutic which can enhance hippocampal BDNF levels could serve as a pharmacological intervention for restoring diabetesassociated learning and memory impairment.

Supplementary Information The online version contains supplementary material available at https://doi.org/10.1007/s12035-021-02441-7.

Acknowledgements The authors would like to thank the University Research Facility in Behavioral and Systems Neuroscience, Hong Kong Polytechnic University for their support. We also thank the technical support from School of Biomedical Sciences, The University of Hong Kong.

Author Contribution Conceptualization: Thomas H Lee, Brian R Christie, Kangguang Lin, Parco Ming-fai Siu, Li Zhang, Tifai Yuen, Pragya Komal, Aimin Xu, Kwok-fai So, and Suk-yu Yau; methodology: Brian R Christie and Suk-yu Yau; formal analysis and investigation: Thomas H Lee, Ahadullah, and Suk-yu Yau; writing - original draft preparation: Thomas H Lee and Suk-yu Yau; writing-review and editing: Thomas H Lee, Ahadullah, Brian R Christie, Kangguang Lin, Parco Ming-fai Siu, Li Zhang, Tifai Yuen, Pragya Komal, Aimin Xu, Kwok-fai So, and Suk-yu Yau; funding acquisition: Suk-yu Yau; resources: Suk-yu Yau; supervision: Suk-yu Yau.

Funding This work was supported by funding (Hong Kong Research Grant Council, Early career scheme: 25100217; General Research Fund: 15100018 and National Science Foundation of China, Young investigator scheme: 81801346) awarded to Suk-yu Yau.

Data Availability Data are available upon request.

\section{Declarations}

Ethics Approval This study was approved by the Animal Subjects Ethics Sub-Committee (ASESC Code: 16-17/10-RS-R-GRF), The Hong Kong Polytechnic University. 
Consent to Participate N/A,

\section{Consent for Publication N/A}

Conflict of Interest The authors declare no competing interests.

Open Access This article is licensed under a Creative Commons Attribution 4.0 International License, which permits use, sharing, adaptation, distribution and reproduction in any medium or format, as long as you give appropriate credit to the original author(s) and the source, provide a link to the Creative Commons licence, and indicate if changes were made. The images or other third party material in this article are included in the article's Creative Commons licence, unless indicated otherwise in a credit line to the material. If material is not included in the article's Creative Commons licence and your intended use is not permitted by statutory regulation or exceeds the permitted use, you will need to obtain permission directly from the copyright holder. To view a copy of this licence, visit http://creativecommons.org/licenses/by/4.0/.

\section{References}

1. Cheng G, Huang C, Deng H, Wang H (2012) Diabetes as a risk factor for dementia and mild cognitive impairment: a meta-analysis of longitudinal studies. Intern Med J. 42(5):484-491

2. Albai O, Frandes M, Timar R, Roman D, Timar B (2019) Risk factors for developing dementia in type 2 diabetes mellitus patients with mild cognitive impairment. Neuropsychiatr Dis Treat. 15:167175

3. Yin QQ, Pei JJ, Xu S, Luo DZ, Dong SQ, Sun MH, You L, Sun ZJ et al (2013) Pioglitazone improves cognitive function via increasing insulin sensitivity and strengthening antioxidant defense system in fructose-drinking insulin resistance rats. PLoS One. 8(3):e59313

4. Gao F, Zang L, Wu DY, Li YJ, Zhang Q, Wang HB, Tian GL, Mu YM (2017) Pioglitazone improves the ability of learning and memory via activating ERK1/2 signaling pathway in the hippocampus of T2DM rats. Neurosci Lett. 651:165-170

5. Ma L, Shao Z, Wang R, Zhao Z, Dong W, Zhang J, Zhang X, Sheng $S$ et al (2015) Rosiglitazone improves learning and memory ability in rats with type 2 diabetes through the insulin signaling pathway. Am J Med Sci. 350(2):121-128

6. Fei L, Yong-Jun H, Zhang-Min M, Bing X, Shuang W, Qian-qian S, Jun L (2015) Rosiglitazone attenuates memory impairment in aged rat with diabetes by inhibiting NF-kappa B signal pathway activation. Exp Clin Endocrinol Diabetes. 123(9):536-542

7. Zhang WJ, Tan YF, Yue JT, Vranic M, Wojtowicz JM (2008) Impairment of hippocampal neurogenesis in streptozotocin-treated diabetic rats. Acta Neurol Scand. 117(3):205-210

8. Magarinos AM, McEwen BS (2000) Experimental diabetes in rats causes hippocampal dendritic and synaptic reorganization and increased glucocorticoid reactivity to stress. Proc Natl Acad Sci U S A. 97(20):11056-11061

9. Kamal A, Biessels GJ, Duis SE, Gispen WH (2000) Learning and hippocampal synaptic plasticity in streptozotocin-diabetic rats: interaction of diabetes and ageing. Diabetologia. 43(4):500-506

10. Manschot SM, Biessels GJ, Cameron NE, Cotter MA, Kamal A, Kappelle LJ, Gispen WH (2003) Angiotensin converting enzyme inhibition partially prevents deficits in water maze performance, hippocampal synaptic plasticity and cerebral blood flow in streptozotocin-diabetic rats. Brain Res. 966(2):274-282

11. Han R, Liu Z, Sun N, Liu S, Li L, Shen Y, Xiu J, Xu Q (2019) BDNF alleviates neuroinflammation in the hippocampus of type 1 diabetic mice via blocking the aberrant HMGB1/RAGE/NFkappaB pathway. Aging Dis. 10(3):611-625

12. Bampi SR, Casaril AM, Domingues M, de Andrade LD, Pesarico AP, Vieira B et al (2020) Depression-like behavior, hyperglycemia, oxidative stress, and neuroinflammation presented in diabetic mice are reversed by the administration of 1-methyl-3-(phenylselanyl)1H-indole. J Psychiatr Res. 120:91-102

13. de la Monte SM, Wands JR (2008) Alzheimer's disease is type 3 diabetes-evidence reviewed. J Diabetes Sci Technol. 2(6):11011113

14. Cotman CW, Berchtold NC (2002) Exercise: a behavioral intervention to enhance brain health and plasticity. Trends Neurosci. 25(6): 295-301

15. Cotman CW, Berchtold NC (2007) Physical activity and the maintenance of cognition: learning from animal models. Alzheimers Dement. 3(2 Suppl):S30-S37

16. Asano RY, Sales MM, Browne RA, Moraes JF, Coelho Junior HJ, Moraes MR et al (2014) Acute effects of physical exercise in type 2 diabetes: a review. World J Diabetes. 5(5):659-665

17. Reisi P, Babri S, Alaei H, Sharifi MR, Mohaddes G, Noorbakhsh SM, Lashgari R (2010) Treadmill running improves long-term potentiation (LTP) defects in streptozotocin-induced diabetes at dentate gyrus in rats. Pathophysiology. 17(1):33-38

18. Stranahan AM, Lee K, Martin B, Maudsley S, Golden E, Cutler RG, Mattson MP (2009) Voluntary exercise and caloric restriction enhance hippocampal dendritic spine density and BDNF levels in diabetic mice. Hippocampus. 19(10):951-961

19. Amati F, Dube JJ, Coen PM, Stefanovic-Racic M, Toledo FG, Goodpaster BH (2009) Physical inactivity and obesity underlie the insulin resistance of aging. Diabetes Care. 32(8):1547-1549

20. Venables MC, Jeukendrup AE (2009) Physical inactivity and obesity: links with insulin resistance and type 2 diabetes mellitus. Diabetes Metab Res Rev. 25(Suppl 1):S18-S23

21. Eaton SB, Eaton SB (2017) Physical inactivity, obesity, and type 2 diabetes: an evolutionary perspective. Res Q Exerc Sport. 88(1):18

22. Rush WA, Whitebird RR, Rush MR, Solberg LI, O'Connor PJ (2008) Depression in patients with diabetes: does it impact clinical goals? J Am Board Fam Med. 21(5):392-397

23. Egede LE, Ellis C (2010) Diabetes and depression: global perspectives. Diabetes Res Clin Pract. 87(3):302-312

24. Holt RI, de Groot M, Golden SH (2014) Diabetes and depression. Curr Diab Rep. 14(6):491

25. Gregg EW, Beckles GL, Williamson DF, Leveille SG, Langlois JA, Engelgau MM, Narayan KM (2000) Diabetes and physical disability among older U.S. adults. Diabetes Care. 23(9):1272-1277

26. Wong E, Backholer K, Gearon E, Harding J, Freak-Poli R, Stevenson C, Peeters A (2013) Diabetes and risk of physical disability in adults: a systematic review and meta-analysis. Lancet Diabetes Endocrinol. 1(2):106-114

27. Lihn AS, Pedersen SB, Richelsen B (2005) Adiponectin: action, regulation and association to insulin sensitivity. Obes Rev. 6(1): $13-21$

28. Kriketos AD, Gan SK, Poynten AM, Furler SM, Chisholm DJ, Campbell LV (2004) Exercise increases adiponectin levels and insulin sensitivity in humans. Diabetes Care. 27(2):629-630

29. Bluher M, Bullen JW Jr, Lee JH, Kralisch S, Fasshauer M, Kloting $\mathrm{N}$ et al (2006) Circulating adiponectin and expression of adiponectin receptors in human skeletal muscle: associations with metabolic parameters and insulin resistance and regulation by physical training. J Clin Endocrinol Metab. 91(6):2310-2316

30. Yau SY, Lee TH, Li A, Xu A, So KF (2018) Adiponectin mediates running-restored hippocampal neurogenesis in streptozotocininduced type 1 diabetes in mice. Front Neurosci. 12:679

31. Ng RC, Jian M, Ma OK (2020) Bunting M. Kwan JS, Zhou GJ, et al. Chronic oral administration of adipoRon reverses cognitive 
impairments and ameliorates neuropathology in an Alzheimer's disease mouse model. Mol Psychiatry

32. Bloemer J, Pinky PD, Smith WD, Bhattacharya D, Chauhan A, Govindarajulu M, et al. Adiponectin knockout mice display cognitive and synaptic deficits. Front Endocrinol (Lausanne). 2019;10: 819.

33. Zhang D, Wang X, Lu XY (2016) Adiponectin exerts neurotrophic effects on dendritic arborization, spinogenesis, and neurogenesis of the dentate gyrus of male mice. Endocrinology. 157(7):2853-2869

34. Yau SY, Li A, Hoo RL, Ching YP, Christie BR, Lee TM et al (2014) Physical exercise-induced hippocampal neurogenesis and antidepressant effects are mediated by the adipocyte hormone adiponectin. Proc Natl Acad Sci U S A. 111(44):15810-15815

35. Zhang D, Wang X, Wang B, Garza JC, Fang X, Wang J, Scherer PE, Brenner R et al (2017) Adiponectin regulates contextual fear extinction and intrinsic excitability of dentate gyrus granule neurons through AdipoR2 receptors. Mol Psychiatry. 22(7):1044-1055

36. Wang P, Liang Y, Chen K, Yau SY, Sun X, Cheng KK et al (2020) Potential involvement of adiponectin signaling in regulating physical exercise-elicited hippocampal neurogenesis and dendritic morphology in stressed mice. Front Cell Neurosci. 14:189

37. Lu B, Nagappan G, Lu Y (2014) BDNF and synaptic plasticity, cognitive function, and dysfunction. Handb Exp Pharmacol. 220: 223-250

38. Choi SH, Bylykbashi E, Chatila ZK, Lee SW, Pulli B, Clemenson $\mathrm{GD}$, et al. Combined adult neurogenesis and BDNF mimic exercise effects on cognition in an Alzheimer's mouse model. Science. 2018;361(6406).

39. Wrann CD, White JP, Salogiannnis J, Laznik-Bogoslavski D, Wu J, Ma D, Lin JD, Greenberg ME et al (2013) Exercise induces hippocampal BDNF through a PGC-1alpha/FNDC5 pathway. Cell Metab. 18(5):649-659

40. Cheng A, Wan R, Yang JL, Kamimura N, Son TG, Ouyang X, Luo Y, Okun E et al (2012) Involvement of PGC-1alpha in the formation and maintenance of neuronal dendritic spines. Nat Commun. 3: 1250

41. Iwabu M, Yamauchi T, Okada-Iwabu M, Sato K, Nakagawa T, Funata M, Yamaguchi M, Namiki S et al (2010) Adiponectin and AdipoR1 regulate PGC-1alpha and mitochondria by $\mathrm{Ca}(2+)$ and AMPK/SIRT1. Nature. 464(7293):1313-1319

42. Okada-Iwabu M, Yamauchi T, Iwabu M, Honma T, Hamagami K, Matsuda K, Yamaguchi M, Tanabe H et al (2013) A smallmolecule AdipoR agonist for type 2 diabetes and short life in obesity. Nature. 503(7477):493-499

43. Nicolas S, Debayle D, Bechade C, Maroteaux L, Gay AS, Bayer P et al (2018) Adiporon, an adiponectin receptor agonist acts as an antidepressant and metabolic regulator in a mouse model of depression. Transl Psychiatry. 8(1):159

44. Lee TH, Christie BR, van Praag H, Lin K, Siu PM-F, Xu A, So KF, Yau SY (2021) AdipoRon treatment induces a dose-dependent response in adult hippocampal neurogenesis. International Journal of Molecular Sciences. 22(4):2068

45. Yau SY, Lau BW, Tong JB, Wong R, Ching YP, Qiu G et al (2011) Hippocampal neurogenesis and dendritic plasticity support running-improved spatial learning and depression-like behaviour in stressed rats. PloS one. 6(9):e24263

46. Woolley CS, Gould E, Frankfurt M, McEwen BS (1990) Naturally occurring fluctuation in dendritic spine density on adult hippocampal pyramidal neurons. J Neurosci. 10(12):4035-4039

47. Yau SY, Li A, Tong JB, Bostrom C, Christie BR, Lee TM, So KF (2016) Chronic corticosterone administration reduces dendritic complexity in mature, but not young granule cells in the rat dentate gyrus. Restorative neurology and neuroscience. 34(5):849-857

48. Yau SY, Bettio L, Chiu J, Chiu C, Christie BR (2018) Fragile-X syndrome is associated with NMDA receptor hypofunction and reduced dendritic complexity in mature dentate granule cells. Front Mol Neurosci. 11:495

49. Hagihara H, Toyama K, Yamasaki N, Miyakawa T (2009) Dissection of hippocampal dentate gyrus from adult mouse. J Vis Exp. 33

50. Yau SY, Bostrom CA, Chiu J, Fontaine CJ, Sawchuk S, Meconi A, Wortman RC, Truesdell E et al (2016) Impaired bidirectional NMDA receptor dependent synaptic plasticity in the dentate gyrus of adult female Fmr1 heterozygous knockout mice. Neurobiology of disease. 96:261-270

51. Yang Q, Zhu G, Liu D, Ju JG, Liao ZH, Xiao YX, Zhang Y, Chao $\mathrm{N}$ et al (2017) Extrasynaptic NMDA receptor dependent long-term potentiation of hippocampal CA1 pyramidal neurons. Sci Rep. 7(1): 3045

52. Liu L, Wong TP, Pozza MF, Lingenhoehl K, Wang Y, Sheng M, Auberson YP, Wang YT (2004) Role of NMDA receptor subtypes in governing the direction of hippocampal synaptic plasticity. Science. 304(5673):1021-1024

53. Jones LJ, Gray M, Yue ST, Haugland RP, Singer VL (2001) Sensitive determination of cell number using the CyQUANT cell proliferation assay. J Immunol Methods. 254(1-2):85-98

54. Pavlov TS, Levchenko V, Karpushev AV, Vandewalle A, Staruschenko A (2009) Peroxisome proliferator-activated receptor gamma antagonists decrease $\mathrm{Na}+$ transport via the epithelial $\mathrm{Na}+$ channel. Mol Pharmacol. 76(6):1333-1340

55. Sharabi K, Lin H, Tavares CDJ, Dominy JE, Camporez JP, Perry RJ, Schilling R, Rines AK et al (2017) Selective chemical inhibition of PGC-1alpha gluconeogenic activity ameliorates type 2 diabetes. Cell. 169(1):148-160 e15

56. Kraeuter AK, Guest PC, Sarnyai Z (1916) The Y-maze for assessment of spatial working and reference memory in mice. Methods Mol Biol. 2019:105-111

57. Wang S, Pan MH, Hung WL, Tung YC, Ho CT (2019) From white to beige adipocytes: therapeutic potential of dietary molecules against obesity and their molecular mechanisms. Food Funct. 10(3):1263-1279

58. Zhou L, Xiao X, Zhang Q, Zheng J, Deng M. Deciphering the antiobesity benefits of resveratrol: the "gut microbiota-adipose tissue" axis. Front Endocrinol (Lausanne). 2019;10:413.

59. Kubota N, Yano W, Kubota T, Yamauchi T, Itoh S, Kumagai H, Kozono H, Takamoto I et al (2007) Adiponectin stimulates AMPactivated protein kinase in the hypothalamus and increases food intake. Cell Metab. 6(1):55-68

60. Jian M, Kwan JS, Bunting M, Ng RC, Chan KH (2019) Adiponectin suppresses amyloid-beta oligomer (AbetaO)-induced inflammatory response of microglia via AdipoR1-AMPK-NFkappaB signaling pathway. J Neuroinflammation. 16(1):110

61. Xu N, Zhang Y, Doycheva DM, Ding Y, Zhang Y, Tang J, Guo H, Zhang JH (2018) Adiponectin attenuates neuronal apoptosis induced by hypoxia-ischemia via the activation of AdipoR1/ APPL $1 /$ LKB $1 /$ AMPK pathway in neonatal rats. Neuropharmacology. 133:415-428

62. van Praag H, Christie BR, Sejnowski TJ, Gage FH (1999) Running enhances neurogenesis, learning, and long-term potentiation in mice. Proc Natl Acad Sci U S A. 96(23):13427-13431

63. McEwen BS, Nasca C, Gray JD (2016) Stress effects on neuronal structure: hippocampus, amygdala, and prefrontal cortex. Neuropsychopharmacology. 41(1):3-23

64. Eadie BD, Redila VA, Christie BR (2005) Voluntary exercise alters the cytoarchitecture of the adult dentate gyrus by increasing cellular proliferation, dendritic complexity, and spine density. J Comp Neurol. 486(1):39-47

65. Patten AR, Sickmann H, Hryciw BN, Kucharsky T, Parton R, Kernick A, Christie BR (2013) Long-term exercise is needed to enhance synaptic plasticity in the hippocampus. Learn Mem. 20(11):642-647 
66. Scarpulla RC (2011) Metabolic control of mitochondrial biogenesis through the PGC-1 family regulatory network. Biochim Biophys Acta. 1813(7):1269-1278

67. LeBleu VS, O'Connell JT, Gonzalez Herrera KN, Wikman H, Pantel K, Haigis MC et al (2014) PGC-1alpha mediates mitochondrial biogenesis and oxidative phosphorylation in cancer cells to promote metastasis. Nat Cell Biol. 16(10):992-1003 1-15

68. Stanton PK, Schanne FA (1986) Hippocampal long-term potentiation increases mitochondrial calcium pump activity in rat. Brain Res. 382(1): 185-188

69. Yau SY, Li A, Zhang ED, Christie BR, Xu A, Lee TM et al (2014) Sustained running in rats administered corticosterone prevents the development of depressive behaviors and enhances hippocampal neurogenesis and synaptic plasticity without increasing neurotrophic factor levels. Cell transplantation. 23(4-5):481-492

70. Johnson RA, Rhodes JS, Jeffrey SL, Garland T Jr, Mitchell GS (2003) Hippocampal brain-derived neurotrophic factor but not neurotrophin-3 increases more in mice selected for increased voluntary wheel running. Neuroscience. 121(1):1-7

71. Wang JQ, Yin J, Song YF, Zhang L, Ren YX, Wang DG et al (2014) Brain aging and AD-like pathology in streptozotocininduced diabetic rats. J Diabetes Res. 2014:796840

72. Leuner B, Shors TJ (2004) New spines, new memories. Mol Neurobiol. 29(2):117-130

73. Redila VA, Christie BR (2006) Exercise-induced changes in dendritic structure and complexity in the adult hippocampal dentate gyrus. Neuroscience. 137(4):1299-1307

74. Stranahan AM, Khalil D, Gould E (2007) Running induces widespread structural alterations in the hippocampus and entorhinal cortex. Hippocampus. 17(11):1017-1022

75. van Praag H, Shubert T, Zhao C, Gage FH (2005) Exercise enhances learning and hippocampal neurogenesis in aged mice. $\mathrm{J}$ Neurosci. 25(38):8680-8685

76. Farmer J, Zhao X, van Praag H, Wodtke K, Gage FH, Christie BR (2004) Effects of voluntary exercise on synaptic plasticity and gene expression in the dentate gyrus of adult male Sprague-Dawley rats in vivo. Neuroscience. 124(1):71-79

77. Massey PV, Johnson BE, Moult PR, Auberson YP, Brown MW, Molnar E, Collingridge GL, Bashir ZI (2004) Differential roles of NR2A and NR2B-containing NMDA receptors in cortical longterm potentiation and long-term depression. J Neurosci. 24(36): 7821-7828

78. Bartlett TE, Bannister NJ, Collett VJ, Dargan SL, Massey PV, Bortolotto ZA, Fitzjohn SM, Bashir ZI et al (2007) Differential roles of NR2A and NR2B-containing NMDA receptors in LTP and LTD in the CA1 region of two-week old rat hippocampus. Neuropharmacology. 52(1):60-70

79. Yau SY, Lee TH, Formolo DA, Lee WL, Li LC, Siu PM et al (2019) Effects of maternal voluntary wheel running during pregnancy on adult hippocampal neurogenesis, temporal order memory, and depression-like behavior in adult female and male offspring. Front Neurosci. 13:470

80. Wang M, Jo J, Song J (2019) Adiponectin improves long-term potentiation in the 5XFAD mouse brain. Sci Rep. 9(1):8918

81. Song J, Choi SM, Whitcomb DJ, Kim BC (2017) Adiponectin controls the apoptosis and the expression of tight junction proteins in brain endothelial cells through AdipoR1 under beta amyloid toxicity. Cell Death Dis. 8(10):e3102

82. Spranger J, Verma S, Gohring I, Bobbert T, Seifert J, Sindler AL, Pfeiffer A, Hileman SM et al (2006) Adiponectin does not cross the blood-brain barrier but modifies cytokine expression of brain endothelial cells. Diabetes. 55(1):141-147

83. Taliaz D, Stall N, Dar DE, Zangen A (2010) Knockdown of brainderived neurotrophic factor in specific brain sites precipitates behaviors associated with depression and reduces neurogenesis. Mol Psychiatry. 15(1):80-92

84. Aarse J, Herlitze S, Manahan-Vaughan D (2016) The requirement of BDNF for hippocampal synaptic plasticity is experience-dependent. Hippocampus. 26(6):739-751

85. Alonso M, Vianna MR, Depino AM (2002) Mello e Souza T, Pereira P, Szapiro G, et al. BDNF-triggered events in the rat hippocampus are required for both short- and long-term memory formation. Hippocampus. 12(4):551-560

86. Klein AB, Williamson R, Santini MA, Clemmensen C, Ettrup A, Rios M, Knudsen GM, Aznar S (2011) Blood BDNF concentrations reflect brain-tissue BDNF levels across species. Int $\mathrm{J}$ Neuropsychopharmacol. 14(3):347-353

87. Xia DY, Huang X, Bi CF, Mao LL, Peng LJ, Qian HR (2017) PGC1 alpha or FNDC5 is involved in modulating the effects of Abeta142 oligomers on suppressing the expression of BDNF, a beneficial factor for inhibiting neuronal apoptosis, Abeta deposition and cognitive decline of APP/PS1 Tg mice. Front Aging Neurosci. 9:65

88. Vaarmann A, Mandel M, Zeb A, Wareski P, Liiv J, Kuum M, Antsov E, Liiv M et al (2016) Mitochondrial biogenesis is required for axonal growth. Development. 143(11):1981-1992

89. Garcia D, Shaw RJ (2017) AMPK: mechanisms of cellular energy sensing and restoration of metabolic balance. Mol Cell. 66(6):789 800. https://doi.org/10.1016/j.molcel.2017.05.032

90. Dasgupta B, Milbrandt J (2009) AMP-activated protein kinase phosphorylates retinoblastoma protein to control mammalian brain development. Dev Cell. 16(2):256-270

91. Kim DM, Leem YH (2016) Chronic stress-induced memory deficits are reversed by regular exercise via AMPK-mediated BDNF induction. Neuroscience. 324:271-285

Publisher's Note Springer Nature remains neutral with regard to jurisdictional claims in published maps and institutional affiliations. 